\title{
Boosting with ALVAC-HIV and AIDSVAX B/E enhances Env constant region 1 and 2 antibody-dependent cellular cytotoxicity
}

\section{By}

David Easterhoff ${ }^{*}$, Justin Pollara1, Kan Luo ${ }^{1}$, William D. Tolbert ${ }^{12}$, Brianna Young ${ }^{11}$,Dieter Mielke$^{1}$, Shalini Jha ${ }^{1}$, Robert J. O'Connell ${ }^{3}$, Sandhya Vasan²,3,10, Jerome Kim² ${ }^{2^{*}}$, Nelson L. Michael $^{2,10}$, Jean-Louis Excler ${ }^{2,10^{* *}}$, Merlin L. Robb ${ }^{2,10}$, Supachai Rerks-Ngarm ${ }^{5}$, Jaranit Kaewkungwal $^{6}$, Punnee Pitisuttithum ${ }^{6}$, Sorachai Nitayaphan ${ }^{7}$, Faruk Sinangil ${ }^{8}$, James Tartaglia ${ }^{9}$, Sanjay Phogat ${ }^{9 \#}$, Thomas B. Kepler ${ }^{4}$, S. Munir Alam ${ }^{1}$, Kevin Wiehe ${ }^{1}$, Kevin O. Saunders ${ }^{1}$, David C. Montefiori', Georgia D. Tomaras ${ }^{1}$, M. Anthony Moody ${ }^{1}$, Marzena Pazgier ${ }^{12}$,Barton F. Haynes $^{1^{*}}$ and Guido Ferrari ${ }^{1^{*}}$

1Duke University, Durham, NC; '2US Military HIV Research Program, Walter Reed Army Institute of Research, Silver Spring, MD ; ${ }^{3}$ U.S. Army Medical Directorate, AFRIMS, Bangkok, Thailand; " Boston University, Boston, MA; ${ }^{5}$ Thai Ministry of Public Health, Nonthaburi, Thailand; ${ }^{6}$ Mahidol University, Bangkok, Thailand; ${ }^{7}$ Royal Thai Army Component, AFRIMS, Bangkok, Thailand; ${ }^{8} \mathrm{Global}$ Solutions of Infectious Diseases, South San Francisco, CA; ${ }^{9}$ Sanofi Pasteur, Swiftwater, PA; NH; ${ }^{10}$ The Henry M. Jackson Foundation for the Advancement of Military Medicine, Bethesda, MD; ${ }^{11}$ Department of Biochemistry and Molecular Biology of University of Maryland, Baltimore, MD USA. ${ }^{12}$ Infectious Diseases Division, Uniformed Services University of the Health Sciences, Bethesda, MD, USA,

** Current affiliation: International Vaccine Institute, Seoul, Republic of Korea

\# Current affiliation: Glaxosmithkline, USA

*Correspondence: david.easterhoff@duke.edu (D.E.), barton.haynes@duke.edu (B.F.H.) and

guido.ferrari@duke.edu and (G.F.)

\section{Significance}

Over one million people become infected with HIV-1 each year making the development of an efficacious HIV-1 vaccine an important unmet medical need. The RV144 human

HIV-1 vaccine-regimen is the only HIV-1 clinical trial to date to demonstrate vaccineefficacy. An area of focus has been on identifying ways by which to improve upon RV144 vaccine-efficacy. The RV305 HIV-1 vaccine-regimen was a follow-up boost of RV144 vaccine-recipients that occurred 6-8 years after the conclusion of RV144. Our 
2

33 studies focused on the effect of delayed boosting in humans on the vaccine-induced antibody repertoire. It was found that boosting with a HIV-1 Env vaccine increased antibody-mediated effector function potency and breadth.

\section{Abstract}

37 Induction of protective antibodies is a critical goal of HIV-1 vaccine development. One strategy is to induce non-neutralizing antibodies that kill virus-infected cells as these antibody specificities have been implicated in slowing HIV-1 disease progression and in protection. HIV-1 Env constant region 1 and 2 (C1C2) antibodies frequently contain potent antibody dependent cellular cytotoxicity (ADCC) making them a vaccine target. Here we explore the effect of delayed and repetitive boosting of RV144 vaccinee recipients with ALVAC/AIDSVAX B/E on the C1C2-specific antibody repertoire. It was found that boosting increased clonal lineage specific ADCC breadth and potency. A ligand crystal structure of a vaccine-induced broad and potent ADCC-mediating C1C2specific antibody showed that it bound a highly conserved Env gp120 epitope. Thus, rationally designed boosting strategies to affinity mature these type of IgG C1C2specific antibody responses may be one method by which to make an improved HIV vaccine with higher efficacy than seen in the RV144 trial.

\section{INTRODUCTION}

CD4-inducible (CD4i) epitopes within HIV-1 envelope (Env) constant regions 1 and $2(\mathrm{C} 1 \mathrm{C} 2)$ are targets for antibodies that mediate antibody dependent cellular cytotoxicity

53 (ADCC) [1]. C1C2-specific antibody epitopes have been termed Cluster A [1] and defined 
indicate that these antibodies bind distinct Env epitopes. The A32 epitope involves a

57 discontinuous sequence within layers 1 and 2 of the inner domain $[4,5]$ while the C11 epitope maps to the inner domain eight-stranded $\beta$ sandwich [6]. Importantly, both antibodies are non-neutralizing for tier 2 HIV strains, but are capable of broad and potent $\operatorname{ADCC}[1,2]$. indicated that ADCC in the presence of low anti-Env IgA responses correlated with decreased HIV-1 acquisition [7]. While antibodies representative of the Env variable region 2 (V2) response inversely correlated with HIV-1 acquisition [7], we previously demonstrated that synergy between A32-blockable C1C2-specific antibodies and V2specific antibodies increased the potency of V2 antibodies induced in the RV144 trial [8].

Here we have studied the effects of late boosting of RV144 vaccinees on affinity maturation and potency of C1C2-specific ADCC antibodies in the RV305 HIV-1 vaccine trial (NCT01435135). We found that ALVAC/AIDSVAX B/E immunizations induced C1C2-specific antibodies and that late booster immunizations increased C1C2-specific antibody variable heavy and variable light $\left(\mathrm{V}_{\mathrm{H}}+\mathrm{V}_{\mathrm{L}}\right)$ chain gene mutation frequencies and increased their ADCC breadth and potency.

AIDSVAX B/E N-terminal deletion alters C1C2-specific antibody responses. AIDSVAX B/E protein used in the RV144 and RV305 HIV-1 vaccine trial had an eleven amino acid $\mathrm{N}$-terminal deletion [9] that removed a majority of the C11-like antibody 
79 the gp120 N-terminal 11 amino acids [10]. To determine if C11 could bind to gp120

80 proteins with an 11 amino acid N-terminal deletion, we assayed A32 and C11 antibodies

81 for binding to full length AE.A244gp120 or to AE.A244gp120 11 (N-terminal 11 aa

82 deleted). Antibody A32 bound to full length AE.A244gp120 and A32 binding was enhanced on AE.A244gp120 11 (Fig. 1A) [9]. In contrast, antibody C11 only bound to

84 the full length AE.A244gp120 (Fig 1A). From these data we concluded that C11-like antibody responses were unlikely to be boosted by AIDSVAX B/E.

A total of 19 RV305-derived NNAbs isolated from four individuals (Table S1 \& S2) were identified that blocked the C1C2 mAb A32 binding to AE.A244gp120 11 (Fig 1B). Compared to previously published RV144 C1C2-specific antibodies [11] the RV305 C1C2-specific antibodies had significantly more $V_{H}$ and $V_{L}$ chain gene mutations (Wilcoxon rank sum test $\mathrm{P}<0.0001$ ) (Fig 1C) suggesting that RV305 boosting induced additional somatic mutations in C1C2-specific antibodies. epitope similar to A32, we used the A32 ligand crystal structure [5] to identify critical A32 antibody contact residues, and then designed an AE.A244gp120 111 mutant protein (AE.A244gp120A11 F35S, H72L, V75A, E106K, D107H, S110A, Q114L) to eliminate A32-like antibody binding (Fig 1A). In ELISA, the RV305 antibody, DH838,

97 was the only antibody with binding eliminated by mutating the A32 epitope (Fig 1D). 
101 C1C2-specific antibodies [11] and these antibodies bound epitopes distinct from A32 102 but in close enough proximity to be sterically cross-blocked by A32 (Fig 1B). assessed for ADCC against a cross-clade panel of HIV-1 infectious molecular clone (IMC) infected CD4+ T cells (HIV-1 AE.CM235, B.WITO, C.TV-1. C.MW965, C.1086C, that accounted for ADCC breadth and potency. Apart from the RV144-derived A32 blockable antibody $\mathrm{CH} 38$, which was naturally an $\lg \mathrm{A}$ antibody but tested here as a recombinant IgG1 antibody, 16/19 RV305 antibodies ranked higher than the RV144 antibodies (Table 1). Next RV305 derived C1C2-specific antibody heavy chain gene

112 mutation frequency was used as a proxy for responsiveness to boosting and compared 113 to the ADCC score. The $\mathrm{V}_{\mathrm{H}}$ mutation frequency (\% nucleotide) inversely correlated with 114 the ADCC score (Spearman Correlation -0.5599; $p$ value $=0.0127)($ Fig S1). However

115 the $V_{H}$ mutation frequency of those antibodies with the highest ADCC scores were above the average heavy chain gene mutation frequency for RV144 (Fig S1 Fig 1C).

117 Thus, while a RV144 boosting regimen was necessary to increase C1C2-specific ADCC breadth and potency, additional boosting with same immunogens may not be beneficial.

119 Boosting of RV144 vaccinees in the RV305 trial increased ADCC breadth and potency of the RV144 derived C1C2-specific, DH677 clonal lineage. Next the C1C2-

121 specific DH677 memory B cell clonal lineage was used to study affinity maturation and 
124 DH677.2, DH677.3 and DH677.4 clonal lineage members were isolated after delayed and repetitive boosting with AIDSVAX B/E alone (RV305 Group II). Thus, this B cell clonal lineage belongs to a long-lived memory B cell pool started by the RV144 vaccine-

127 regimen and boosted many years later with the RV305 vaccine-regimen (Fig 2). The

$128 \mathrm{DH} 677$ clonal lineage was assayed by surface plasmon resonance for binding to the

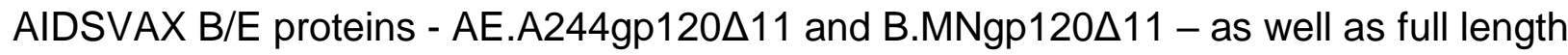
AE.A244gp120. DH677 unmutated common ancestor (UCA) did not bind to

B.MNgp120 11 , had minimal binding to the full length AE.A244gp120 and this binding was enhanced with AE.A244gp120 111 (Fig 2 and Fig S2). The RV305 boosts more than doubled the $\mathrm{V}_{H}$ chain gene mutation frequency from 1.04\% (DH677.1; RV144) up to $4.51 \%$ (DH677.4; RV305) which resulted in 100-fold increase in apparent affinity for the AIDSVAX B/E proteins (DH677.1 AE.A244gp120 $\Delta 11 \mathrm{KD}=45.2$ \& B.MNgp120 $\Delta 11$ $K_{D}=219$ to $D H 677.4$ AE.A244gp120 $111 \mathrm{~K}=0.49$ \& B.MNgp120 $\left.11 \mathrm{~K}_{\mathrm{D}}=2.86\right)$ and also improved binding to full length AE.A244gp120 (Fig 2 and Fig S2). clonal lineage against a cross-clade panel of IMC infected cells (AE.CM235, B.WITO, C.TV-1, C.MW965, C.1086C, C.DU151 and C.DU422). The RV144 prime-boost immunization regimen minimally increased ADCC breadth and potency (DH677 UCA ADCC Score $=-2.32 ;$ DH677.1 ADCC Score $=-2.20$ (see methods)). Conversely, RV305 boosting substantially increased ADCC breadth and potency (DH677.3 ADCC

144 Score $=4.56)($ Fig 2 and Fig S3). These data indicated that the RV144 prime-boost

145 regimen was insufficient to fully affinity mature this $\mathrm{C} 1 \mathrm{C} 2$-specific $\mathrm{B}$ cell clonal lineage. 
Rather RV305 trial boosting of this particular RV144 vaccinee profoundly enhanced

Crystal structure of the potent ADCC-mediating antibody DH677.3. We next determined the crystal structures of the antigen binding fragment (Fab) of the highest ranking RV305 ADCC antibody DH677.3 (Table 1) - alone and in complex with clade AE

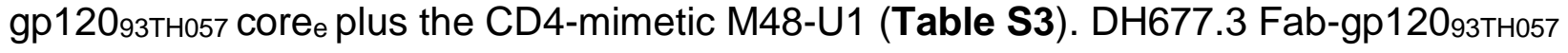
core $_{e}-$ M48U1 complex (Fig 3) showed that, similar to other Cluster A antibodies, DH677.3 approaches gp120 at the face that is buried in the native Env trimer [3-5] and binds the C1C2 region exclusively within the gp120 inner domain. gp120 residues involved in DH677.3 binding map to the base of the 7-stranded $\beta$-sandwich (residues 82, 84, 86-87, 222-224, 244-246, and 491-492) and its extensions into the mobile layers 1 (residues 53, $60,70-80$ ) and 2 (residues 218-221). By docking at the layer $1 / 2 / \beta$-sandwich junction the antibody buried surface area (BSA) utilizes $248 \AA^{2}$ of the $\beta$-sandwich, $542 \AA$ of layer 1 and $135 \AA^{2}$ of layer 2 (Table S4). The majority of contacts providing specificity involve a network of hydrogen bonds and a salt bridge (Fig 3A, inset) contributed by the antibody heavy chain and gp120 side chain atoms of layer 1 ( $\alpha$ turn connecting the $\beta 1--\beta 0$ strands, $\mathrm{D}^{78}$ and $\mathrm{N}^{80}$ ) and the 7-stranded- $\beta$-sandwich (strand $\beta 7, \mathrm{Q}^{246}$ ). The contacts provided by the light chain are less specific and consist of hydrogen bonds to the gp120 main chain atoms and hydrophobic contacts within a hydrophobic cleft formed at the layer $1 / 2 / \beta$ sandwich junction (Fig 3B and C). Overall DH677.3 utilizes all six of its complementary determining regions (CDRs), and relies approximately equally on both heavy chain and

167 light chain with a total buried surface area (BSA) of $973 \AA^{2}: 498 \AA^{2}$ for the light chain and 
169 contact residues are conserved in $>80 \%$ of sequences in the HIV Sequence Database

170 Compendium

171 (https://www.hiv.lanl.gov/content/sequence/HIV/COMPENDIUM/compendium.html) with

17215 of 29 being effectively invariant (>99\% conserved) (Fig 3B).

173 Comparison of the DH677.3 mode of binding and epitope footprint to Cluster A prototype antibodies. Antigen complex structures of mAb A32 and N12-i3 (C11-like) [3, 6], antibodies isolated from HIV-1-infected individuals, confirm that DH677.3 recognized

176 a unique epitope between the $\mathrm{A} 32$ and $\mathrm{C} 11$ antibody-binding sites involving Env epitope

177 elements of both (Fig 4). While the A32 antibody epitope consists exclusively of gp120

178 mobile layers 1 and 2 (76\% and $24 \%$ of gp120 BSA, respectively; Table S4, Fig 4 B and

C), DH677.3 relies less on layers 1 and 2 (53\% and 14\% of gp120 BSA, respectively) and effectively utilizes the gp120 7-stranded $\beta$-sandwich (24\% of gp120 BSA) (Table S4, Fig

4 B and C). The ability to recognize the 7-stranded $\beta$-sandwich renders DH677.3 similar to the $\mathrm{C} 11$-like antibody N12-i3, which almost exclusively depends on the $\beta$-sandwich for binding (94\% of its total gp120 BSA; Table S4, Fig 4 B and C). Interestingly, N12-i3 and other $\mathrm{C} 11$-like antibodies require the $\mathrm{N}$-terminus of gp120 for binding and recognize a unique gp120 conformation formed by docking of the gp120 N-terminus as an $8^{\text {th }}$ strand to the $\beta$-sandwich to form an 8-stranded- $\beta$-sandwich structure [6]. The DH677.3 complex crystals were obtained with gp12093тн057 core e which lacks the $\mathrm{N}$-terminus ( $\Delta 11$ aa deletion) and therefore the direct judgment, based on structure, whether or not the $8^{\text {th }}$ strand is involved in binding was not possible (Fig 3). However, we were able to model

190 the N/C-termini-gp12093тн057 core from the N12-i3 Fab complex structure (PDB code:

191 5W4L) to the DH677.3 Fab-gp12093тн057 core $_{\mathrm{e}}$-M48U1 complex without any steric 
192 clashes (Fig 4A, inset). Both the conformation and orientation of CDR $\mathrm{H} 1$ and 2 of DH677.3 allowed easy access to the 8-stranded- $\beta$-sandwich structure and enabled contacts to the $8^{\text {th }}$ strand. These data indicated that $\mathrm{DH} 677.3$ is capable of accommodating both the 7 and 8 -stranded- $\beta$-sandwich conformations of gp120 with effective contacts to the $8^{\text {th }}$ strand. Thus, the DH677.3 C1C2 antibody has a unique

197 binding angle to the $\mathrm{C} 1 \mathrm{C} 2$ region compared to $\mathrm{C} 1 \mathrm{C} 2$ antibodies $\mathrm{C} 11$ and $\mathrm{A} 32$.

\section{DH677 lineage antibodies mediate ADCC against CD4 downmodulated HIV-1}

199 infected cells. During natural infection the HIV-1 accessory protein Nef downregulates

200 CD4 expression on the surface of virus infected cells $[12,13]$. Cell surface expressed

201 CD4 facilitates the exposure of CD4i Env epitopes - like C1C2 - by binding to cotarget cells infected with IMCs containing the Renilla luciferase (LucR) reporter gene, which restricts Nef expression leading to incomplete CD4 downregulation [15]. Nevertheless, Vpu expression can compensate for Nef function and induce CD4 downregulation during the 72 hour incubation of the target cells before assays were 207 performed. To exclude any possible impact of this technical aspect of IMCs with LucR 208 on our ADCC results, full length IMCs $(n=7)$ that do not contain a report gene were used 209 to evaluate ADCC of the affinity matured RV305 C1C2-specific antibodies DH677.3 and

210 DH677.4 and A32 [2], against target cells positive for intracellular p24 (p24+) and with

211 downregulated CD4 (CD4-). As clade CRF01_AE possess a histidine at Env HXB2

212 position 375 that influences sensitivity to CD4i antibody binding and ADCC $[16,17]$ only 213 clade B and clade C isolates were used. 
When evaluating elimination of total p24+ cells no significant difference

215

216

217

218

219

220

221

222

223

224

225

226

227

228

229

230

231

232

233

234

235

236

(Wilcoxon rank sum test; $p>0.05$ ) in specific killing was noted among the three different antibodies (Fig 5A). However, when infected cells were separated into p24+CD4+ (Fig 5B) and p24+CD4- (Fig 5C) it was found that the RV305-boosted DH677.3 antibody was significantly better (Wilcoxon rank sum test $p=0.03$ ) at mediating ADCC against p24+ CD4- infected cells (Fig 5C) when compared to A32. These data indicate that the DH677 clonal lineage epitope was more frequently exposed on Env conformers on the surface of IMC infected cells even in the context of CD4 downmodulation making this epitope a highly desirable NNAb vaccine target and important consideration in the setting of cure AIDS initiatives.

\section{DISCUSSION}

In this study it was found that late boosting of RV144 vaccinees increased C1C2specific antibody $V_{H}+V_{L}$ chain gene mutation frequency and increased clonal lineage specific ADCC breadth and potency (Table 1, Fig 2). Most RV305 derived antibodies had broader and more potent ADCC activity than the RV144 derived antibodies (Table 1) but $V_{H}$ chain gene mutation frequency and the ADCC score did not directly correlate (Fig S1). While RV305 was necessary to mature C1C2-specific antibody responses, additional boosting with ALVAC/AIDSVAX B/E would not increase ADCC breadth and potency. Likely rationally designed sequential [18] boosting immunogens to select for critical mutations [19] that directionally affinity mature highly functional

ALVAC/AIDSVAX B/E-induced C1C2-specific antibodies are needed.

Improving vaccine-induced NNAb effector function will also require more detailed immunological studies on the timing and frequency of boosting. In VAX003 
(NCT00002441) and VAX004 (NCT00002441) trials frequent protein immunizations skewed Env-specific antibody subclass usage from the highly functional lgG3 to IgG4 [20-22]. The RV305 boosts that were studied here occurred several years (6-8yrs) later, unlike previous HIV-1 vaccine trials. Whether the boosting interval can be shortened without skewing antibody subclass usage is not known, but it is possible that boosting with long rest intervals ( $\geq 1-2$ years) will be necessary.

vaccine trial contained an $\mathrm{N}$-terminal 11 amino acid deletion with important implications for NNAb induction. Previously it was shown that this modification enhanced exposure of the $\mathrm{C} 1 \mathrm{C} 2$ region and V2 loop [9]. Here we show that this modification disrupts C11like antibody binding (Fig 1) but does creates a germline-targeting immunogen for DH677-like B cell lineages (Fig S2). Ligand crystal structure analysis found that DH677.3 recognized a unique C1C2 epitope that involves parts of epitope footprints of C1C2 Cluster A antibodies A32 and N12-i3 (C11-like) as well as new elements of the

251 inner domain Layer 1 and the 7-stranded- $\beta$-sandwich (Fig 3 and 4). The DH677.3

252 epitope is positioned midway between the A32 and N12-i3 binding sites with most

253 residues being highly conserved. Interestingly, DH677.3 binds at the edge of the gp120 254 inner domain 7-stranded $\beta$-sandwich and with layers 1 and 2 with a binding mode that 255 allows it to accommodate the addition of the $\mathrm{N}$-terminus as the $8^{\text {th }}$ strand to the 7256 stranded- $\beta$-sandwich, a gp120 conformation emblematic of the late stages of HIV entry 257 and recognized by $\mathrm{C} 11$ and $\mathrm{C} 11$-like antibodies [6]. Most likely this feature allows

258 DH677.3 to recognize a broader range of Env targets, emerging in both the early (when 
260 of the viral entry process. Identification of a stage 2A of the HIV-1 Env expressed on

261 the surface of infected cells in presence of the CD4 molecule or CD4 mimetics reiterate

262 the importance of targeting these epitopes by vaccine induced responses as detected in

263 our assays [23] . In addition, a model of DH677.3 in complex with gp120 antigen bound

264 to a CD4 of a target/infected cell confirms that the recognition site and angle of

265 approach position the DH677.3 IgG for easy access for effector cell recognition and Fc-

266 effector complex formation (Fig 4A).

ADCC-mediating antibodies have been shown to reduce mother-to-child HIV-1 transmission [24-26],slow virus disease progression [26-28] and in RV144 correlated with reduced risk of infection in vaccine recipients with lower anti-Env plasma IgA responses [7]. Synergy between the RV144 C1C2 and V1V2 mAbs suggest a role for

271 the $\mathrm{C} 1 \mathrm{C} 2$ plasma responses that could not be directly identify by the correlates of

272 protection study. Based on the data reported in this study and by Zoubchenok et al [16]

273 , it is clear that the magnitude of Env susceptibility to ADCC by the C1C2-specific Ab

274 responses is not consistent as suggested by the conserved sequence of this region and 275 varies according to the conformational stage of the HIV-1 envelope. That DH677.3 was 276 better than A32 at mediating ADCC against HIV-1 clade B and C CD4 down-modulated 277 cells (Fig 5) make this antibody an attractive candidate for targeting HIV-1 infected cells 278 in vivo in the setting of HIV-1 infection. We have previously shown that the $\mathrm{C} 1 \mathrm{C} 2$ 279 antibody A32 when formulated as a bi-specific antibody can potently opsonize and kill 280 HIV-1 infected CD4+ T cells [29]. Whether DH677.3-type of antibodies are superior to 281 A32 for targeting virus-infected cells remains to be determined. 
In summary, our data demonstrate that if the RV144 vaccine trial had been boosted, ADCC-mediating antibodies would have undergone affinity maturation for both ADCC potency and breadth of recognition of HIV-1-infected CD4+ T cells. Rationally designed subsequent boosting strategies to immunofocus IgG C1C2-specific response towards DH677-like antibody specificities may be one method by which to provide greater protection than observed in the RV144 HIV-1 vaccine trial.

\section{METHODS}

Ethics Statement. The RV305 clinical trial (NCT01435135) was a boost given to 162 RV144 clinical trial participants (NCT00223080) six-eight years after the conclusion of RV144 [30]. Donors used in this study were from groups boosted either with AIDSVAX B/E + ALVAC-HIV (vCP1521) (Group I) or AIDSVAX B/E alone (Group II). clinical trial participants.The Duke University Health System Institutional Review Board approved all human specimen handling.

Antigen-specific single-cell sorting. $1 \times 10^{7}$ peripheral blood mononuclear cells (PBMCs) per vaccine-recipient were stained with AE.A244gp120 111 fluorescently labelled proteins and a human B cell flow cytometry panel. Viable antigen-specific B cells (AqVd- CD14- CD16- CD3- CD19+ IgD-) were single-cell sorted with a BD stored at $-80^{\circ} \mathrm{C}$ for RT-PCR. 
Single-cell reverse transcriptase PCR. Single B cell cDNA was generated with random hexamers using SSIII. The antibody variable heavy and light chain variable regions were PCR amplified using AmpliTaq360 Master Mix (Applied Biosystems). PCR products were purified (Qiagen, Valencia, CA) and sequenced by Genewiz. Gene rearrangements, clonal relatedness, unmutated common ancestors and intermediate ancestor inferences were made using Cloanalyst [31]. DH677 clonal lineage tree was generated using FigTree.

Monoclonal antibody production. PCR-amplified heavy and light chain gene sequences were transiently expressed as previously described [32]. Ig containing cell

314 culture supernatants were used for ELISA binding assays. For large scale expression,

$315 V_{H}$ and $V_{L}$ chain genes were synthesized ( $V_{H}$ chain in the $\lg G 14 A$ backbone) and transformed into DH5 $\alpha$ cells (GeneScript, Piscataway, NJ). Plasmids were expressed in

317 Luria Broth, purified (Qiagen, Valencia, CA) and Expi293 cells were transfected using 318 ExpiFectamine $^{\text {TM }}$ (Life Technologies, Carlsbad, CA) following the manufacturers 319 protocol. After five days of incubation at $37^{\circ} \mathrm{C} 5 \% \mathrm{CO}_{2}$ the Ig containing media was 320 concentrated, purified with Protein A beads and the antibody buffer exchanged into 321 PBS.

Antibody binding and blocking assays. Direct ELISAs were performed as

323 previously described [32]. Briefly, 384-well microplates were coated overnight with

$32430 \mathrm{ng} /$ well of protein. Antibodies were diluted and add for one hour. Binding was

325 detected with an anti-lgG-HRP (Rockland) and developed with SureBlue Reserve TMB

326 One Component (KPL). Plates were read on a plate reader (Molecular Devices) at 
450nm. A32-blocking assays were performed by adding the RV305 antibodies followed by biotinylated A32 and detecting with streptavidin HRP.

Neutralization assays. TZM-bl neutralization assays were performed in the Montefiori lab as previously described [33]. Data are reported as $\mathrm{IC}_{50}$ titers for 331 antibodies. replication-competent IMC designed to encode the env genes of CM235 (subtype A/E; (subtype C; GeneBank No. FJ444395), TV-1 (subtype C; GeneBank No. HM215437), MW96.5 (subtype C; GeneBank No.), DU151 (subtype C; GeneBank No. DQ411851), DU422 (subtype C; GeneBank No. DQ411854) in cis within an Nef deficient isogenic backbone that expresses the Renilla luciferase reporter gene [34]. The subtype AE Env-IMC-LucR viruses used were the NL-LucR.T2A-AE.CM235-ecto (IMCcM235)

340 (plasmid provided by Dr. Jerome Kim, US Military HIV Research Program), and clinical env isolates from the RV144 trial that were built on the 40061-LucR virus backbone. All

342 the other IMCs were built using the original NL-LucR.T2A-ENV.ecto backbone as originally described by [35] Reporter virus stocks were generated by transfection of 293T cells with proviral IMC plasmid DNA, and virus titer was determined on TZM-bl

345 cells for quality control [35] infected with HIV-1 IMCs as previously described [36]. Briefly, IMCs were titrated in order to achieve maximum expression within 48-72 hours post-infection as determined by detection of Luciferase activity and intra-cellular p24 expression. IMC infections 
350 were performed by incubation of the optimal dilution of virus with CEM.NKRccR5 cells for

3510.5 hour at $37^{\circ} \mathrm{C}$ and $5 \% \mathrm{CO}_{2}$ in presence of DEAE-Dextran $(7.5 \mu \mathrm{g} / \mathrm{ml})$. The cells were

352 subsequently resuspended at $0.5 \times 10^{6} / \mathrm{ml}$ and cultured for $48-72$ hours in complete

353 medium containing $7.5 \mu \mathrm{g} / \mathrm{ml}$ DEAE-Dextran. For each ADCC assay, we monitored the

354 frequency infected target cells by intracellular p24 staining. Assays performed using

355 infected target cells were considered reliable if cell viability was $\geq 60 \%$ and the

percentage of viable $\mathrm{p} 24^{+}$target cells on assay day was $\geq 20 \%$.

Luciferase ADCC Assay. ADCC activity was determined by a luciferase (LuC)-

used at an effector to target ratio of 30:1. Recombinant mAbs were tested across a

367 intensity (relative light units, RLU) generated by the presence of residual intact target cells that have not been lysed by the effector population in the presence of ADCCmediating mAb (ViviRen substrate, Promega, Madison, WI). The \% of specific killing was calculated using the formula: percent specific killing $=[$ (number of RLU of target

371 and effector well - number of RLU of test well)/number of RLU of target and effector

372 well] $\times 100$. In this analysis, the RLU of the target plus effector wells represents 
17

373 spontaneous lysis in absence of any source of Ab. The ADCC endpoint concentration

$374(E C)$, defined as the lowest concentration of mAb capable of mediating ADCC in our in

375 vitro assay, was calculated by interpolation of the mAb concentration that intersected

376 the positive cutoff of $15 \%$ specific killing. The RSV-specific mAb Palivizumab was used

377 as a negative control.

378 ADCC Score. Antibodies were tested across a range of concentrations using 5 -fold serial

379 dilutions starting at $50 \mu \mathrm{g} / \mathrm{mL}$. Since the dilution curves are not monotonic due to pro380 zone effect of mAbs, non-parametric area under the curve (AUC) was calculated using 381 trapezoidal rule with activity less than $15 \%$ set to $0 \%$. For calculating a weighted average

382 to obtain a score for ADCC activity explaining both potency and breadth of the mAbs, in 383 this study we have used Principal Component Analysis (PCA) to compute an ADCC score. PCA is the most commonly used method to reduce the dimensionality of the data 385 set [41]. It uses Eigen vector decomposition of the correlation matrix of the variables, where each variable is represented by a viral isolate. Most of the shared variance of the

387 correlations of ADCC AUC is explained by first principal component (PC1) [42]. Ideally, one would want to explain $70 \%$ of the variance but should not be at the expense of adding 389 principal components with an Eigenvalue less than 1 [43].

In this study we a panel of $7 \mathrm{HIV}$ isolates was tested which implies that our data set has seven dimensions. ADCC activity was measured as AUC . In our analysis PC1 and PC2 392 have Eigen values above 1 and together account for $80.57 \%$ variance (Table S5). Scores 393 obtained from the first Principal Component can be interpreted as weighted average of 394 the 7 isolates that would account for both potency as well as breadth of the mAbs [43]. 395 Higher PC1 score would mean that mAb has a higher breadth as well as potency for 
ADCC activity. To calculate the ADCC score, the standardized AUC value for each monoclonal antibody is calculated for each viral isolate, multiplied by factor loading of the given viral isolate and then these products are added together. Standardized AUC values imply zero mean and unit standard deviation. The AUC values below the value of mean AUC will result in negative PC1 scores.

Infection of primary cells with HIV-1 IMCs. Infectious molecular clones either subtype B or $\mathrm{C}$ viruses from the $\mathrm{CHAVI}$ acute infection cohort $(\mathrm{CH} 77, \mathrm{CH} 264$, $\mathrm{CH} 0470, \mathrm{CH} 042, \mathrm{CH} 185, \mathrm{CH} 162$ and $\mathrm{CH} 236)$ were constructed as previously described $[44,45]$ and used to infect primary CD4+ cells. To infect cells, cryopreserved peripheral blood mononuclear cells (PBMCs) were thawed and stimulated in R20 media (RPMI

407 media (Invitrogen) with 20\% Fetal Bovine Serum (Gemini Bioproducts), 2mM L-

408 glutamine (Invitrogen), $50 \mathrm{U} / \mathrm{mL}$ penicillin (Invitrogen), and $50 \mu \mathrm{g} / \mathrm{mL}$ Gentamicin

409 (Invitrogen)) supplemented with IL-2 (30U/mL, Proleukin), anti-CD3 (25ng/mL clone

410 OKT-3, Invitrogen) and anti-CD28 (25ng/mL, BD Biosciences) antibodies for 72 hours at

$411 \quad 37^{\circ} \mathrm{C}$ in $5 \% \mathrm{CO}_{2} . \mathrm{CD} 8$ cells were depleted from the PBMCs using CD8 microbeads

412 (Miltenyi Biotec, Germany) according to the Manufacturer's instructions and $1.5 \times 10^{6}$

413 cells were infected using $1 \mathrm{~mL}$ virus supernatant by spinoculation $(1125 \times \mathrm{g})$ for 2 hours

414 at $20^{\circ} \mathrm{C}$. After spinoculation, $2 \mathrm{~mL}$ of R20 supplemented with IL-2 was added to each 415 infection and infections were left for 72 hours. Infected cells were used if viability was $416>70 \%$ and more than $5 \%$ of cells were p $24+$. 
418 PBMCs cells were used as targets and autologous cryo-preserved PBMCs rested overnight in R10 supplemented with 10ng/ml of IL-15 (Miltenyi Biotec) were used as a source of effector cells. Infected and uninfected target cells were labelled with a

421 fluorescent target-cell marker (TFL4; Oncolmmunin) and a viability marker (NFL1;

422 Oncolmmunin) for $15 \mathrm{~min}$ at $37^{\circ} \mathrm{C}$, as specified by manufacturer. The labeling of the 423 target cells with these two markers allowed to clearly identify only the live viable cells in 424 our gating strategy and exclude artifacts related to the presence of dead cells staining.

425 Cells were washed in R10 and adjusted to a concentration of $0.2 \times 10^{6}$ cells $/ \mathrm{mL}$. PBMCs 426 were then added to target cells at an effector/target ratio of $30: 1\left(6 \times 10^{6}\right.$ cells $\left./ \mathrm{mL}\right)$. The 427 target/effector cell suspension was plated in V-bottom 96-well plates and co-cultured 428 with $10 \mu \mathrm{g} / \mathrm{mL}$ of each $\mathrm{mAb}$. Co-cultures were incubated for $6 \mathrm{~h}$ at $37^{\circ} \mathrm{C}$ in $5 \% \mathrm{CO}_{2}$.

429 After the incubation period, cells were washed and stained with anti-CD4-PerCP-Cy5.5

430 (eBioscience, clone OKT4) at a final dilution of 1:40 in the dark for $20 \mathrm{~min}$ at room 431 temperature (RT). Cells were then washed, resuspended in $100 \mu \mathrm{L} /$ well

432 Cytofix/Cytoperm (BD Biosciences), incubated in the dark for 20 min at $4{ }^{\circ} \mathrm{C}$, washed in 433 1x Cytoperm wash solution (BD Biosciences) and co-incubated with anti-p24 antibody 434 (clone KC57-RD1; Beckman Coulter) to a final dilution of 1:100, and incubated in the 435 dark for 25 min at $4{ }^{\circ} \mathrm{C}$. Cells were washed three times with Cytoperm wash solution 436 and resuspended in $125 \mu \mathrm{L}$ PBS-1\% paraformaldehyde. The samples were acquired 437 within $24 \mathrm{~h}$ using a BD Fortessa cytometer. The appropriate compensation beads were 438 used to compensate the spill over signal for the four fluorophores. Data analysis was 439 performed using FlowJo 9.6.6 software (TreeStar). Mock-infected cells were used to 440 appropriately position live cell p24+/- and CD4+/- gates. 
20

441 Specific killing was determined by the reduction in \% of viable p24+ cells in the

442 presence of mAbs after taking into consideration non-specific killing, and was calculated

443 as:

444

$$
\frac{\mathrm{p} 24 \%(\text { target }+ \text { effector cells })-\mathrm{p} 24 \% \text { (targets }+ \text { effectors }+ \text { mAb/plasma })}{\text { p24\% (target }+ \text { effector cells })}
$$

CH65 (an anti-influenza monoclonal antibody, kindly provided by Dr. Moody) was used and then negative values were rounded to $0 \%$.

449 Surface plasmon resonance - The binding and kinetic rates measurement of gp120

450 proteins against RV305 mAbs were obtained by surface plasmon resonance (SPR)

451 using the Biacore 3000 instrument (GE Healthcare). SPR measurements were

452 performed using a CM5 sensor chip with anti-human IgG Fc antibody directly

453 immobilized to a level of 9000-11000RU (response unit). Antibodies were then

454 captured at $5 \mathrm{ul} / \mathrm{min}$ for 60 s to a level of 100-300RU. For binding analyses, the gp120

455 proteins were diluted to approximately 1000nM in PBS and injected over the captured

456 antibodies for 3 minutes at 30ul/min. For kinetics measurements, the gp120 proteins

457 were diluted from 5-750nM and injected using a high performance kinetics injection for 5

458 minutes at $50 \mathrm{uL} / \mathrm{min}$. This was followed by a dissociation period of 600 s and surface

459 regeneration with Glycine $\mathrm{pH} 2.0$ for 20 s. Results were analyzed using the Biacore

460 BiaEvaluation Software (GE Healthcare). Negative control antibody (Ab82) and blank

461 buffer binding were used for double reference subtraction to account for non-specific

462 protein binding and signal drift. Subsequent curve fitting analysis was performed using a 
1:1 Langmuir model with a local Rmax and the reported rate constants are representative of two measurements.

Protein preparation and complex crystallization DH677.3 Fab alone was grown and crystalized at concentration $\sim 10 \mathrm{mg} / \mathrm{ml}$. The structure was solved by molecular

467 replacement with PDB ID 3QEG in space group P2 1 to a resolution of $2.6 \AA$. Clade A/E 468 93TH057 gp120 core e, (gp12093тн057 core, residues 42-492 (Hxbc2 numbering)), lacking the $\mathrm{V} 1, \mathrm{~V} 2$ and $\mathrm{V} 3$ variable loops and containing a H375S mutation to allow binding of 470 the CD4 mimetic M48U1 [46] was used to obtain crystals of DH677.3 Fab-antigen 471 complex. gp12093тн057 core was prepared and purified as described in [3]. 472 Deglycosylated gp12093тно57 core e was first mixed with CD4 mimetic peptide M48U1 at a 473 molar ratio of 1:1.5 and purified through gel filtration chromatography using a Superdex $47420016 / 60$ column (GE Healthcare, Piscataway, NJ). After concentration, the gp1209зтн057 475 core $_{e}-\mathrm{M} 48 \mathrm{U} 1$ complex was mixed with a $20 \%$ molar excess of DH677.3 Fab and passed 476 again through the gel filtration column equilibrated with $5 \mathrm{mM}$ Tris- $\mathrm{HCl}$ buffer $\mathrm{pH} 7.2$ and $477100 \mathrm{mM}$ ammonium acetate. The purified complex was concentrated to $\sim 10 \mathrm{mg} / \mathrm{ml}$ for 478 crystallization experiments. The structure was solved by molecular replacement using 479 the DH677.3 Fab and PDB ID 3TGT as searching models in space group P1 to a 480 resolution $3.0 \AA$. The final $R_{\text {factor }} / R_{\text {free }}(\%)$ for the Fab structure is $19.9 / 26.1$ and the final $481 R_{\text {factor }} / R_{\text {free }}$ for the complex is $21.4 / 27.4$ (Table S3). The PDB IDs for the deposited 482 structures are 6MFJ and 6MFP respectively. In each case the asymmetric unit of the 483 crystal contained two almost identical copies of Fab or the Fab- gp12093тн057 coree 484 complex (Fig S2) 
22

Crystallization and Data collection Initial crystal screens were done in vapor-diffusion hanging drop trials using commercially available sparse matrix crystallization screens from Hampton Research (Index), Emerald BioSystems (Precipitant Wizard Screen) and Molecular Dimensions (Proplex and Macrosol Screens). The screens were monitored periodically for protein crystals. Conditions that produced crystals were then further optimized to produce crystals suitable for data collection. DH677.3 Fab crystals were grown from 20\% PEG 3000, $100 \mathrm{mM}$ HEPES pH 7.5, and $200 \mathrm{mM}$ sodium chloride. DH677.3 complex crystals were grown from 25\% PEG 4000 and 100 mM MES pH 5.5. Crystals were briefly soaked in crystallization solution plus 20\% MPD before being flash frozen in liquid nitrogen prior to data collection.

Data collection and structure solution Diffraction data were collected at the Stanford Synchrotron Radiation Light Source (SSRL) at beam line BL12-2 equipped with a Dectris Pilatus area detector. All data were processed and reduced with HKL2000 [47]. Structures were solved by molecular replacement with Phaser [48] from the CCP4 suite [49]. The DH677.3 Fab structure was solved based on the coordinates of the N12-i2 Fab (PDB: 3QEG), and the DH677.3 complex was then solved with coordinates from the DH677.3 Fab model, gp120 (PDB: 3TGT), and M48U1 (PDB: 4JZW). Refinement was carried out with Refmac [50] and/or Phenix [51]. Refinement was coupled with manual refitting and rebuilding with COOT [52]. Data collection and refinement statistics are shown in Table 1.

Structure validation and analysis The quality of the final refined models was monitored using the program MolProbity [53]. Structural alignments were performed using the program Isqkab from the CCP4 suite [49]. The PISA [54] webserver was used 
508 to determine contact surfaces and residues. All illustrations were prepared with the

509 PyMol Molecular Graphic suite (http://pymol.org) (DeLano Scientific, San Carlos, CA,

510 USA). Conservation of the DH677.3 epitope was calculated using the HIV Sequence

511 Database Compendium

512 (https://www.hiv.lanl.gov/content/sequence/HIV/COMPENDIUM/compendium.html)

513 comparing gp120 residues relative to Clade B Hxbc2. Only unique sequences in the 514 database having an equivalent residue at each position were included in the calculated 515 percentage representing approximately 32,000 sequences on average.

516 Statistical Methods For luciferase based ADCC assay background correction was

517 performed by subtracting the highest value of percent specific killing induced by $\mathrm{CH} 65$ 518 and then rounding off the negative values to zero. In order to assess if two groups have 519 different response pairwise comparisons between groups was conducted using 520 Wilcoxon rank sum test. Statistical analysis was performed using SAS software (SAS 521 Institute Inc., Cary, N.C.).

FIGURE LEGENDS

524 Figure 1. Identification of RV305 C1C2-specific antibodies. (A) The C1C2-specific 525 antibodies A32 or C11 were assayed by direct binding ELISA for reactivity with full 526 length AE.A244gp120 or AE.A244g120 11 . An A32-specific mutant protein was 527 designed (AE.A244g120411 F35S H72L V75A E106K D107H S110A Q114L) to identify 528 A32-like antibody responses. 19B antibody was used as a positive control and $\mathrm{CH} 65$ as a negative control. (B) RV305 non-neutralizing antibodies were assayed for A32blocking by ELISA. (C) RV305 non-neutralizing A32-blockable antibody heavy and light 
531 chain gene sequence mutation frequencies were analyzed by Cloanalyst (Kepler et al.,

532 2014) and compared to previously published RV144 heavy and light chain gene

533 sequence mutation frequencies (\% nucleotide) (Bonsignori et al., 2012).Statistical

534 significance was determined using a Wilcoxon rank sum test. Red bar represents that

535 mean (D) RV305 non-neutralizing A32-blockable antibody were assayed by direct

536 binding ELISA to AE.A244g120 11 and AE.A244g120 111 F35S H72L V75A E106K

537 D107H S110A Q114L. Data are expressed as \% binding the mutant protein relative to

538 WT. Shown are the mean with standard deviation of two independent experiments.

Figure 2. RV305 boosting increased the apparent affinity and antibody dependent

DH677 memory B cell clonal lineage. DH677.1 antibody was isolated by antigen-

DH677.4 were isolated by antigen-specific single-cell sorting PBMC collected after the

545 intermediate ancestors and unmutated common ancestor was inferred using Clonalayst

546 [31]. Recombinantly expressed antibodies were assayed by biolayer interferometry for

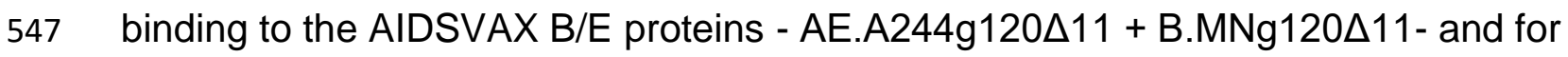

548 antibody dependent cellular cytotoxicity (ADCC) against AE.C235, B.WITO, C.TV-1,

549 C.MW965, C.1086C, C.DU151 and C.DU422 Renilla luciferase reporter gene infectious

550 molecular clone infected cells. An ADCC score (see methods) was used to account for

551 breadth and potency.

552 Figure 3. Crystal structure of the DH677.3 Fab-gp12093тH057 coree-M48U1 complex.

553 (A) The overall structure of the complex is shown as a ribbon diagram (left) and with the 
25

554 molecular surface displayed over the Fab molecule (middle), colored based on electrostatic charge, red negative and blue positive. The gp120 outer domain is gray and inner domain colored to indicate inner domain mobile layer 1 (yellow), 2 (cyan), 3

557 (light orange) and the 7-stranded b-sandwich (magenta). Complementary determining

558 regions (CDRs) are colored: $\mathrm{CDR} \mathrm{H} 1$ (light blue), $\mathrm{CDR} \mathrm{H} 2$ (dark green), $\mathrm{CDR} \mathrm{H} 3$

559 (black), CRL1 (light green), CDR L2 (blue) and CDRL3 (brown). A blow-up view shows the network of hydrogen $(\mathrm{H})$ bonds formed at the Fab-gp120 interface. $\mathrm{H}$-bonds

561 contributed by side chain and main chain atoms of gp120 residues are colored in 562 magenta and blue, respectively. (B) Antibody buried surface area (BSA) and gp120 residues forming DH677.3 epitope are shaded in blue according to BSA (antibody) and

564 percent conservation of gp120 residues (Env). gp120 main chain (blue) and side chain 565 (red) hydrogen bonds $(\mathrm{H})$ and salt bridges $(\mathrm{S})$ are shown above the residue. $(\mathrm{C})$ The

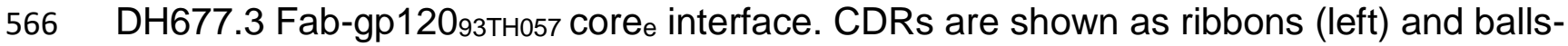
567 and-sticks of residues contributing the binding (right) over the gp120 core. The 568 molecular surface of gp120 is colored as in (A) (left) and by electrostatic potential 569 (right).

Figure 4. Recognition of HIV-1 Env by DH677.3 and other Cluster A antibodies. (A)

571 The overlay of DH677.3 and Cluster A antibodies A32 and N12-i3 (C11-like) bound to

572 the gp120 core. Crystals structures of the gp120 antigen in complex with the Fab of

573 DH677.3, A32 (PDB code 4YC2) and N12-i3 (PDB code 5W4L) were superimposed

574 based on gp120. The $\mathrm{d} 1$ and $\mathrm{d} 2 \mathrm{domains}$ of the target cell receptor CD4 was added to

575 replace peptide mimetic M48U1 of the DH677.3 Fab-gp12093тн057 core $-\mathrm{M} 48 \mathrm{U} 1$

576 complex. Molecular surfaces are displayed over Fab molecules and colored in lighter 
577 and darker shades of brown, blue and green for the heavy and light chains of DH677.3, A32 and N12-i3, respectively. A blow up view shows details of the DH677.3 interaction with the 8 -stranded $\beta$-sandwich of the gp120 inner domain. The $8^{\text {th }}$ strand (colored in blue) formed by the $11 \mathrm{~N}$-terminal residues of gp120 in the N12-i3 bound conformation (PDB: 5W4L) was modeled into the DH677.3 Fab-gp12093тн057 coree-M48U1 complex. $\mathrm{CHR} \mathrm{H1}$ and 2 of DH677.3 are colored light blue and dark green, respectively. (B) and

epitope footprint (shown in red) is plotted on the gp120 surface with layers colored as in

Figure 1 with the A32 and N12-i2 epitope footprints shown in black. In (C) the DH677.3,

chain (+) and main chain (-) contact residues are colored green for hydrophobic, blue for corresponding sequence. Buried surface residues as determined by PISA are shaded.

\section{Figure 5. RV305 derived C1C2-specific antibody DH677.3 is significantly better}

$B$ and clade $C$ full length infectious molecular clones (IMC) that do not contain a 
cytotoxicity against AE.CM235, B.WITO, C.TV-1, C.MW965, C.1086C, C.DU151 and C.DU422 infectious molecular clone infected cells. Antibodies were ranked using an ADCC Score that accounts for breadth and potency (see methods). Number of strains recognized was determined by ADCC endpoint concentration $>40 \mu \mathrm{g} / \mathrm{mL}$.

Figure S1. RV305 C1C2-specific antibody ADCC score inversely correlate with antibody mutation frequency. Correlation between RV305 antibody heavy chain gene mutation frequency (\% nucleotide; Cloanalyst) [31] and ADCC score (see

methods) was calculated with SAS (Spearman Correlation $=-0.5599 ; p$ value $=0.0127$ ).

Figure S2. RV305 boosting increased affinity of the C1C2-specific RV144 derived

\section{DH677 memory B cell clonal lineage to the AIDSVAX B/E proteins. DH677.1}

vaccine trial. DH677.2, DH677.3 and DH677.4 were isolated by antigen-specific single-

612 cell sorting PBMC collected after the second boost AIDSVAX B/E (RV305 Group II)

613 given in RV305 ( 7yrs later). The intermediate ancestors and unmutated common

614 ancestor was inferred using Clonalayst [31]. Recombinantly expressed antibodies were

615 assayed by surface plasmon resonance for binding to the AIDSVAX B/E proteins -

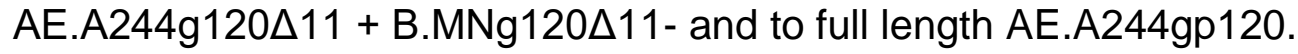

617 Figure S3. Boosting in RV305 increased DH677 B cell clonal lineage cross-clade 
622 infected cells. Data are shown as radar plots with an ADCC score (see methods) that

623 accounts for ADCC breadth and potency.

624 Figure S4. Comparison of the two copies of the DH677.3 Fab-gp12093тH057 core $_{\mathrm{e}}$ M48U1 complex and the two Fab copies in the apo Fab structure from the asymmetric unit of crystals. (A) The root mean square deviation (RMSD) between complex copies is $0.946 \AA$ for main chain residues. (B) The RMSD between the Fab copies in the apo Fab structure is $0.540 \AA$ for main chain residues. (C) Comparison of

629 the free and bound DH677.3 Fab. The $\alpha$-carbon backbone diagram of superposition of 630 the structures of DH677.3 Fab alone (dark cyan-heavy chain and light cyan-light chain) 631 and N5-i5 Fab bound to CD4-triggered gp120 (dark brown-heavy chain and light brown632 light chain). The average RMSD between free and bound Fabs is $0.818 \AA$ for main 633 chain residues.

634 Figure S5. Antibody contact residues. mAb side chain (+) and main chain (-) contact 635 residues colored green for hydrophobic, blue for hydrophilic and black for both as 636 determined by a $5 \AA$ cut off value over the corresponding sequence. CDRs are colored

637 as in Figure 1 and buried surface residues as determined by PISA are shaded.

639 antibodies. RT-PCR amplified variable heavy and variable light chain genes were 640 Sanger sequenced (Genewiz) and analyzed with Cloanalyst [31].

641 Table S2. A32-blocking antibodies do not neutralize HIV-1. (A) Recombinantly expressed antibodies were assayed in the TZM-bl neutralization assay against 
29

643 autologous and heterologous Tier 1 and Tier 2 isolates. No neutralization was detected.

644 Data are shown as EC50 $(\mu \mathrm{g} / \mathrm{mL})$

645 Table S3. DH677.3 structural data collection and refinement statistics

Table S4. Details of the DH677.3, A32, and N12-i3 interfaces based on the

647 DH677.3-gp12093тно57Core e-M48U1, A32 Fab-ID293тн057, and N12-i3 Fab-

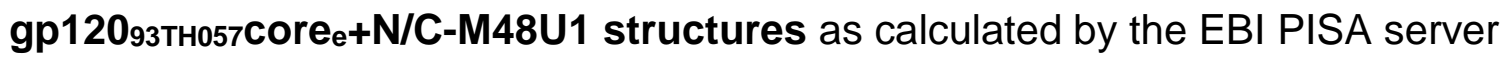

649 (http://www.ebi.ac.uk/msd-srv/prot int/cgi-bin/piserver). The two copies in the

650 asymmetric unit of the DH677.3, A32, and N12-i3 complexes are averaged in the table.

\section{ACKNOWLEDGEMENTS}

653 The authors would like to acknowledge the Duke Human Vaccine Institute Flow

654 Cytometry Facility (Durham, NC), Duke Human Vaccine Institute Viral Genetic Analysis

655 Facility (Durham, NC) and the following individuals for their expert technical assistance:

656 flow cytometry - Derek Cain, Patrice McDermott and Dawn Jones Marshall, conjugated 657 antigens - Lawrence Armand, transient transfections - Andrew Foulger, Erika Dunford 658 and Kedamawit Tilahun, ELISA - Rob Parks, Callie Vivian and Maggie Barr, Antibody 659 Expression - Giovanna Hernandez, Esther Lee, Emily Machiele and Rachel Reed, 660 Neutralization Assays - Amanda Eaton, Celia C. LeBranche, Peter Gao, Kelli Greene 661 and Hongmei Gao, Biolayer Interferometry - Kara Anasti. From project management 662 Cynthia Nagle and Kelly Soderberg. We also thank all of the RV144 and RV305 clinical 663 trial team members and participants. This work was primarily supported by a 664 Collaboration for AIDS Vaccine Discovery Grant OPP1114721 from the Bill \& Melinda 
Gates Foundation to BFH, and by NIH grants NIAID R01 Al116274 and R01 Al129769 to MP, NIAID P01 Al120756 to GT, and a Henry M. Jackson Foundation for the

Advancement of Military Medicine \#829295 grant to BFH.

\section{AUTHOR CONTRIBUTION}

Conceptualization, D.E., B.F.H., J.P., M.P., G.F.; Methodology, D.E., B.F.H., J.P., G.F.;

Software, K.W., T.B.K.; Validation, D.E., J.P., S.J., M.P., G.F.; Formal Analysis, S.J.,

K.W.; Investigation, D.E., J.P., K.L., W.D.T., B.Y., D.M.; Resources, R.J.O., S.V., J.K., M.P., G.D.T., B.F.H., G.F.

\section{DECLARATION OF INTEREST}

680

B.F.H., G.F. and D.E. have patents submitted on antibodies listed in this paper.

\section{DISCLAIMER}

The views expressed are those of the authors and should not be construed to represent the positions of the Uniformed Services University, U.S. Army, Department of Defense or the Department of Health and Human Services. The investigators have adhered to the policies for protection of human subjects as prescribed in AR-70. 

and effector function among human antibodies to HIV-1 envelope glycoprotein epitopes exposed by CD4 binding. Proceedings of the National Academy of Sciences of the United States of America. 2013;110(1):E69-78. doi: 10.1073/pnas.1217609110. PubMed PMID: 23237851; PubMed Central PMCID: PMC3538257.

2. Ferrari G, Pollara J, Kozink D, Harms T, Drinker M, Freel S, et al. An HIV-1 gp120 envelope human monoclonal antibody that recognizes a $\mathrm{C} 1$ conformational epitope mediates potent antibody-dependent cellular cytotoxicity (ADCC) activity and defines a common ADCC epitope in human HIV-1 serum. Journal of virology. 2011;85(14):7029-36. doi: 10.1128/JVI.00171-11. PubMed PMID: 21543485; PubMed Central PMCID: PMC3126567. dependent cellular cytotoxicity response implicated in reduced risk for HIV-1 infection. Journal of virology. 2014;88(21):12895-906. doi: 10.1128/JVI.02194-14. PubMed PMID: 25165110; PubMed Central PMCID: PMC4248932.

705

706

4. Tolbert WD, Gohain N, Veillette M, Chapleau JP, Orlandi C, Visciano ML, et al. Paring Down HIV Env: Design and Crystal Structure of a Stabilized Inner Domain of HIV-1 gp120 Displaying a Major ADCC Target of the A32 Region. Structure. 2016;24(5):697-709. doi: 10.1016/j.str.2016.03.005. PubMed PMID: 27041594; PubMed Central PMCID: PMC4856543. i3 and Antibody JR4 in Complex with gp120 Define More Cluster A Epitopes Involved in Effective Antibody-Dependent Effector Function against HIV-1. Journal of virology. 2015;89(17):8840-54. doi: 10.1128/JVI.01232-15. PubMed PMID: 26085162; PubMed Central PMCID: PMC4524080.

6. Tolbert WD, Gohain N, Alsahafi N, Van V, Orlandi C, Ding S, et al. Targeting the Late Stage of HIV1 Entry for Antibody-Dependent Cellular Cytotoxicity: Structural Basis for Env Epitopes in the C11 Region. Structure. 2017;25(11):1719-31 e4. doi: 10.1016/j.str.2017.09.009. PubMed PMID: 29056481; PubMed Central PMCID: PMC5677539.

7. Haynes BF, Gilbert PB, McElrath MJ, Zolla-Pazner S, Tomaras GD, Alam SM, et al. Immunecorrelates analysis of an HIV-1 vaccine efficacy trial. The New England journal of medicine. 2012;366(14):1275-86. doi: 10.1056/NEJMoa1113425. PubMed PMID: 22475592; PubMed Central PMCID: PMC3371689.

8. Pollara J, Bonsignori M, Moody MA, Liu P, Alam SM, Hwang KK, et al. HIV-1 vaccine-induced C1 and V2 Env-specific antibodies synergize for increased antiviral activities. Journal of virology. 2014;88(14):7715-26. doi: 10.1128/JVI.00156-14. PubMed PMID: 24807721; PubMed Central PMCID: PMC4097802.

9. Alam SM, Liao HX, Tomaras GD, Bonsignori M, Tsao CY, Hwang KK, et al. Antigenicity and immunogenicity of RV144 vaccine AIDSVAX clade E envelope immunogen is enhanced by a gp120 Nterminal deletion. Journal of virology. 2013;87(3):1554-68. doi: 10.1128/JVI.00718-12. PubMed PMID: 23175357; PubMed Central PMCID: PMC3554162.

10. Pitisuttithum P, Rerks-Ngarm S, Bussaratid V, Dhitavat J, Maekanantawat W, Pungpak S, et al. Safety and reactogenicity of canarypox ALVAC-HIV (VCP1521) and HIV-1 gp120 AIDSVAX B/E vaccination in an efficacy trial in Thailand. PloS one. 2011;6(12):e27837. doi: 10.1371/journal.pone.0027837. PubMed PMID: 22205930; PubMed Central PMCID: PMC3244387.

11. Bonsignori M, Pollara J, Moody MA, Alpert MD, Chen X, Hwang KK, et al. Antibody-dependent cellular cytotoxicity-mediating antibodies from an HIV-1 vaccine efficacy trial target multiple epitopes 
and preferentially use the VH1 gene family. Journal of virology. 2012;86(21):11521-32. doi: 10.1128/JVI.01023-12. PubMed PMID: 22896626; PubMed Central PMCID: PMC3486290.

12. Wildum S, Schindler M, Munch J, Kirchhoff F. Contribution of Vpu, Env, and Nef to CD4 downmodulation and resistance of human immunodeficiency virus type 1-infected T cells to superinfection. Journal of virology. 2006;80(16):8047-59. doi: 10.1128/JVI.00252-06. PubMed PMID: 16873261; PubMed Central PMCID: PMC1563805.

13. Arganaraz ER, Schindler M, Kirchhoff F, Cortes MJ, Lama J. Enhanced CD4 down-modulation by late stage HIV-1 nef alleles is associated with increased Env incorporation and viral replication. The Journal of biological chemistry. 2003;278(36):33912-9. doi: 10.1074/jbc.M303679200. PubMed PMID: 12816953.

14. Veillette M, Desormeaux A, Medjahed H, Gharsallah NE, Coutu M, Baalwa J, et al. Interaction with cellular CD4 exposes HIV-1 envelope epitopes targeted by antibody-dependent cell-mediated cytotoxicity. Journal of virology. 2014;88(5):2633-44. doi: 10.1128/JVI.03230-13. PubMed PMID: 24352444; PubMed Central PMCID: PMC3958102.

15. Prevost J, Richard J, Medjahed H, Alexander A, Jones J, Kappes JC, et al. Incomplete Downregulation of CD4 Expression Affects HIV-1 Env Conformation and Antibody-Dependent Cellular Cytotoxicity Responses. Journal of virology. 2018;92(13). doi: 10.1128/JVI.00484-18. PubMed PMID: 29669829; PubMed Central PMCID: PMC6002730.

16. Zoubchenok D, Veillette M, Prevost J, Sanders-Buell E, Wagh K, Korber B, et al. Histidine 375 Modulates CD4 Binding in HIV-1 CRF01_AE Envelope Glycoproteins. Journal of virology. 2017;91(4). doi: 10.1128/JVI.02151-16. PubMed PMID: 27928014; PubMed Central PMCID: PMC5286895.

17. Prevost J, Zoubchenok D, Richard J, Veillette M, Pacheco B, Coutu M, et al. Influence of the Envelope gp120 Phe 43 Cavity on HIV-1 Sensitivity to Antibody-Dependent Cell-Mediated Cytotoxicity Responses. Journal of virology. 2017;91(7). doi: 10.1128/JVI.02452-16. PubMed PMID: 28100618; PubMed Central PMCID: PMC5355605.

18. Haynes BF, Kelsoe G, Harrison SC, Kepler TB. B-cell-lineage immunogen design in vaccine development with HIV-1 as a case study. Nature biotechnology. 2012;30(5):423-33. doi: 10.1038/nbt.2197. PubMed PMID: 22565972; PubMed Central PMCID: PMC3512202.

19. Wiehe K, Bradley T, Meyerhoff RR, Hart C, Williams WB, Easterhoff D, et al. Functional Relevance of Improbable Antibody Mutations for HIV Broadly Neutralizing Antibody Development. Cell host \& microbe. 2018;23(6):759-65 e6. doi: 10.1016/j.chom.2018.04.018. PubMed PMID: 29861171. 20. Chung AW, Ghebremichael M, Robinson H, Brown E, Choi I, Lane S, et al. Polyfunctional Fceffector profiles mediated by IgG subclass selection distinguish RV144 and VAX003 vaccines. Science translational medicine. 2014;6(228):228ra38. doi: 10.1126/scitranslmed.3007736. PubMed PMID: 24648341.

21. Karnasuta C, Akapirat S, Madnote S, Savadsuk H, Puangkaew J, Rittiroongrad S, et al. Comparison of Antibody Responses Induced by RV144, VAX003, and VAX004 Vaccination Regimens. AIDS research and human retroviruses. 2017;33(5):410-23. doi: 10.1089/AID.2016.0204. PubMed PMID: 28006952; PubMed Central PMCID: PMC5439458.

22. Yates NL, Liao HX, Fong Y, deCamp A, Vandergrift NA, Williams WT, et al. Vaccine-induced Env V1-V2 IgG3 correlates with lower HIV-1 infection risk and declines soon after vaccination. Science translational medicine. 2014;6(228):228ra39. doi: 10.1126/scitransImed.3007730. PubMed PMID: 24648342; PubMed Central PMCID: PMC4116665.

23. Alsahafi N, Bakouche N, Kazemi M, Richard J, Ding S, Bhattacharyya S, et al. An Asymmetric Opening of HIV-1 Envelope Mediates Antibody-Dependent Cellular Cytotoxicity. Cell host \& microbe. 2019;25(4):578-87 e5. Epub 2019/04/12. doi: 10.1016/j.chom.2019.03.002. PubMed PMID: 30974085. 24. Ljunggren K, Moschese V, Broliden PA, Giaquinto C, Quinti I, Fenyo EM, et al. Antibodies mediating cellular cytotoxicity and neutralization correlate with a better clinical stage in children born to 

human immunodeficiency virus-infected mothers. The Journal of infectious diseases. 1990;161(2):198202. PubMed PMID: 2299204.

25. Nag P, Kim J, Sapiega V, Landay AL, Bremer JW, Mestecky J, et al. Women with cervicovaginal antibody-dependent cell-mediated cytotoxicity have lower genital HIV-1 RNA loads. The Journal of infectious diseases. 2004;190(11):1970-8. doi: 10.1086/425582. PubMed PMID: 15529262; PubMed Central PMCID: PMC3119045.

26. Lambotte O, Ferrari G, Moog C, Yates NL, Liao HX, Parks RJ, et al. Heterogeneous neutralizing antibody and antibody-dependent cell cytotoxicity responses in HIV-1 elite controllers. Aids. 2009;23(8):897-906. doi: 10.1097/QAD.0b013e328329f97d. PubMed PMID: 19414990; PubMed Central PMCID: PMC3652655.

27. Baum LL, Cassutt KJ, Knigge K, Khattri R, Margolick J, Rinaldo C, et al. HIV-1 gp120-specific antibody-dependent cell-mediated cytotoxicity correlates with rate of disease progression. Journal of immunology. 1996;157(5):2168-73. PubMed PMID: 8757343.

28. Lambotte O, Pollara J, Boufassa F, Moog C, Venet A, Haynes BF, et al. High antibody-dependent cellular cytotoxicity responses are correlated with strong CD8 T cell viral suppressive activity but not with B57 status in HIV-1 elite controllers. PloS one. 2013;8(9):e74855. doi: 10.1371/journal.pone.0074855. PubMed PMID: 24086385; PubMed Central PMCID: PMC3781132. 29. Sung JA, Pickeral J, Liu L, Stanfield-Oakley SA, Lam CY, Garrido C, et al. Dual-Affinity Re-Targeting proteins direct T cell-mediated cytolysis of latently HIV-infected cells. The Journal of clinical investigation. 2015;125(11):4077-90. doi: 10.1172/JCI82314. PubMed PMID: 26413868; PubMed Central PMCID: PMC4639974.

30. Rerks-Ngarm S, Pitisuttithum P, Excler JL, Nitayaphan S, Kaewkungwal J, Premsri N, et al. Randomized, Double-Blind Evaluation of Late Boost Strategies for HIV-Uninfected Vaccine Recipients in the RV144 HIV Vaccine Efficacy Trial. The Journal of infectious diseases. 2017;215(8):1255-63. doi: 10.1093/infdis/jix099. PubMed PMID: 28329190; PubMed Central PMCID: PMC5853427.

31. Kepler TB, Munshaw S, Wiehe K, Zhang R, Yu JS, Woods CW, et al. Reconstructing a B-Cell Clonal Lineage. II. Mutation, Selection, and Affinity Maturation. Frontiers in immunology. 2014;5:170. doi: 10.3389/fimmu.2014.00170. PubMed PMID: 24795717; PubMed Central PMCID: PMC4001017. 32. Easterhoff D, Moody MA, Fera D, Cheng H, Ackerman M, Wiehe K, et al. Boosting of HIV envelope CD4 binding site antibodies with long variable heavy third complementarity determining region in the randomized double blind RV305 HIV-1 vaccine trial. PLoS pathogens. 2017;13(2):e1006182. doi: 10.1371/journal.ppat.1006182. PubMed PMID: 28235027; PubMed Central PMCID: PMC5342261. 33. Montefiori DC. Evaluating neutralizing antibodies against HIV, SIV, and SHIV in luciferase reporter gene assays. Current protocols in immunology. 2005; Chapter 12:Unit 12 1. doi: 10.1002/0471142735.im1211s64. PubMed PMID: 18432938.

34. Edmonds TG, Ding H, Yuan X, Wei Q, Smith KS, Conway JA, et al. Replication competent molecular clones of HIV-1 expressing Renilla luciferase facilitate the analysis of antibody inhibition in PBMC. Virology. 2010;408(1):1-13. doi: 10.1016/j.virol.2010.08.028. PubMed PMID: 20863545; PubMed Central PMCID: PMC2993081.

35. Adachi A, Gendelman HE, Koenig S, Folks T, Willey R, Rabson A, et al. Production of acquired immunodeficiency syndrome-associated retrovirus in human and nonhuman cells transfected with an infectious molecular clone. Journal of virology. 1986;59(2):284-91. PubMed PMID: 3016298; PubMed Central PMCID: PMC253077.

36. Pollara J, Hart L, Brewer F, Pickeral J, Packard BZ, Hoxie JA, et al. High-throughput quantitative analysis of HIV-1 and SIV-specific ADCC-mediating antibody responses. Cytometry Part A : the journal of the International Society for Analytical Cytology. 2011;79(8):603-12. doi: 10.1002/cyto.a.21084. PubMed PMID: 21735545; PubMed Central PMCID: PMC3692008. 
37. Liao HX, Bonsignori M, Alam SM, McLellan JS, Tomaras GD, Moody MA, et al. Vaccine induction of antibodies against a structurally heterogeneous site of immune pressure within HIV-1 envelope protein variable regions 1 and 2. Immunity. 2013;38(1):176-86. doi: 10.1016/j.immuni.2012.11.011. PubMed PMID: 23313589; PubMed Central PMCID: PMC3569735.

38. Trkola A, Matthews J, Gordon C, Ketas T, Moore JP. A cell line-based neutralization assay for primary human immunodeficiency virus type 1 isolates that use either the CCR5 or the CXCR4 coreceptor. Journal of virology. 1999;73(11):8966-74. PubMed PMID: 10516002; PubMed Central PMCID: PMC112928.

39. Koene HR, Kleijer M, Algra J, Roos D, von dem Borne AE, de Haas M. Fc gammaRIIla-158V/F polymorphism influences the binding of IgG by natural killer cell Fc gammaRIlla, independently of the Fc gammaRIIla-48L/R/H phenotype. Blood. 1997;90(3):1109-14. PubMed PMID: 9242542.

40. Bruhns $P$, lannascoli B, England P, Mancardi DA, Fernandez N, Jorieux S, et al. Specificity and affinity of human Fcgamma receptors and their polymorphic variants for human IgG subclasses. Blood. 2009;113(16):3716-25. doi: 10.1182/blood-2008-09-179754. PubMed PMID: 19018092.

41. Hotelling H. Analysis of a complex of statistical variables into principal components. Journal of Educational Psychology. 1933;24(6):417-41. doi: 10.1037/h0071325.

42. Moody MA, Pedroza-Pacheco I, Vandergrift NA, Chui C, Lloyd KE, Parks R, et al. Immune perturbations in HIV-1-infected individuals who make broadly neutralizing antibodies. Science immunology. 2016;1(1):aag0851. Epub 2017/08/08. doi: 10.1126/sciimmunol.aag0851. PubMed PMID: 28783677; PubMed Central PMCID: PMCPMC5589960.

43. Jackson JE. A user's guide to principal components: John Wiley \& Sons; 2005.

44. Salazar-Gonzalez JF, Salazar MG, Keele BF, Learn GH, Giorgi EE, Li H, et al. Genetic identity, biological phenotype, and evolutionary pathways of transmitted/founder viruses in acute and early HIV1 infection. The Journal of experimental medicine. 2009;206(6):1273-89. doi: 10.1084/jem.20090378. PubMed PMID: 19487424; PubMed Central PMCID: PMC2715054.

45. Ochsenbauer C, Edmonds TG, Ding H, Keele BF, Decker J, Salazar MG, et al. Generation of transmitted/founder HIV-1 infectious molecular clones and characterization of their replication capacity in CD4 T lymphocytes and monocyte-derived macrophages. Journal of virology. 2012;86(5):2715-28. doi: 10.1128/JVI.06157-11. PubMed PMID: 22190722; PubMed Central PMCID: PMC3302286.

46. Martin L, Stricher F, Misse D, Sironi F, Pugniere M, Barthe P, et al. Rational design of a CD4 mimic that inhibits HIV-1 entry and exposes cryptic neutralization epitopes. Nat Biotechnol. 2003;21(1):71-6. PubMed PMID: 12483221.

47. Otwinowski Z, Minor W, Charles W. Carter, Jr. Processing of X-ray diffraction data collected in oscillation mode. Methods in Enzymology. Volume 276: Academic Press; 1997. p. 307-26.

48. McCoy AJ. Solving structures of protein complexes by molecular replacement with Phaser. Acta Crystallogr D Biol Crystallogr. 2007;63(Pt 1):32-41. Epub 2006/12/14. doi: S0907444906045975 [pii] 10.1107/S0907444906045975. PubMed PMID: 17164524.

49. N. CCP. The CCP4 suite: programs for protein crystallography. Acta Crystallogr D Biol Crystallogr. 1994;50(Pt 5):760-3. Epub 1994/09/01. doi: 10.1107/S0907444994003112

S0907444994003112 [pii]. PubMed PMID: 15299374.

50. Murshudov GN, Vagin AA, Dodson EJ. Refinement of macromolecular structures by the maximum-likelihood method. Acta Crystallogr D Biol Crystallogr. 1997;53(Pt 3):240-55. Epub 1997/05/01. doi: 10.1107/S0907444996012255

S0907444996012255 [pii]. PubMed PMID: 15299926. 
874 51. Adams PD, Grosse-Kunstleve RW, Hung LW, loerger TR, McCoy AJ, Moriarty NW, et al. PHENIX: 875 building new software for automated crystallographic structure determination. Acta Crystallogr D Biol 876 Crystallogr. 2002;58(Pt 11):1948-54. PubMed PMID: 12393927.

877 52. Emsley P, Cowtan K. Coot: model-building tools for molecular graphics. Acta Crystallogr D Biol 878 Crystallogr. 2004;60(Pt 12 Pt 1):2126-32. Epub 2004/12/02. doi: S0907444904019158 [pii]

879 10.1107/S0907444904019158. PubMed PMID: 15572765.

880 53. Chen VB, Arendall WB, 3rd, Headd JJ, Keedy DA, Immormino RM, Kapral GJ, et al. MolProbity: 881 all-atom structure validation for macromolecular crystallography. Acta Crystallogr D Biol Crystallogr.

882 2010;66(Pt 1):12-21. Epub 2010/01/09. doi: S0907444909042073 [pii]

883 10.1107/S0907444909042073. PubMed PMID: 20057044; PubMed Central PMCID: PMC2803126.

$884 \quad 54$. Krissinel E, Henrick K. Inference of macromolecular assemblies from crystalline state. J Mol Biol. 885 2007;372(3):774-97. Epub 2007/08/08. doi: S0022-2836(07)00642-0 [pii]

886 10.1016/j.jmb.2007.05.022. PubMed PMID: 17681537. 
bioRxiv preprint doi: https://doi.org/10.1101/632844; this version posted May 9 , 2019. The copyright holder for this preprint (which was not certified by peer review) is the author/funder, who has granted bioRxiv a license to display the preprint in perpetuity. It is made available under aCC-BY-ND 4.0 International license.

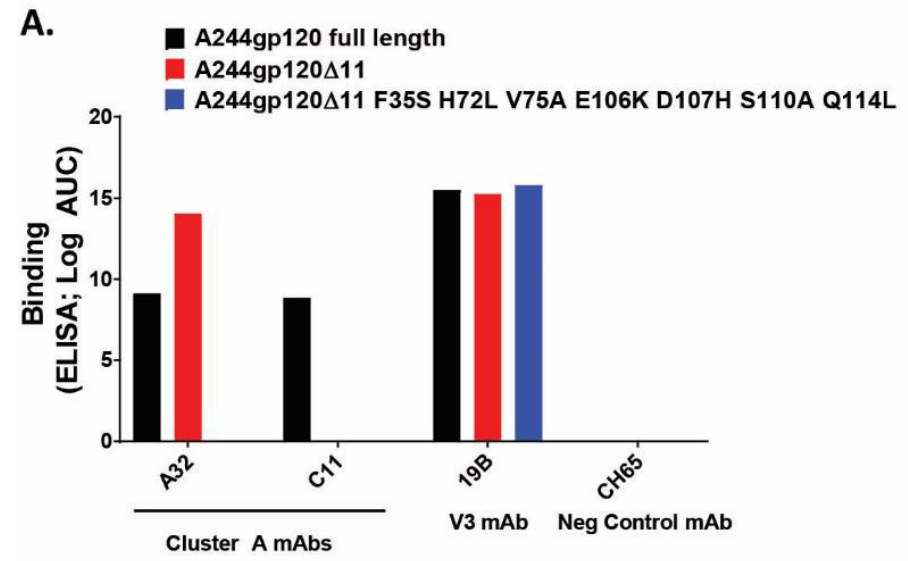

C.

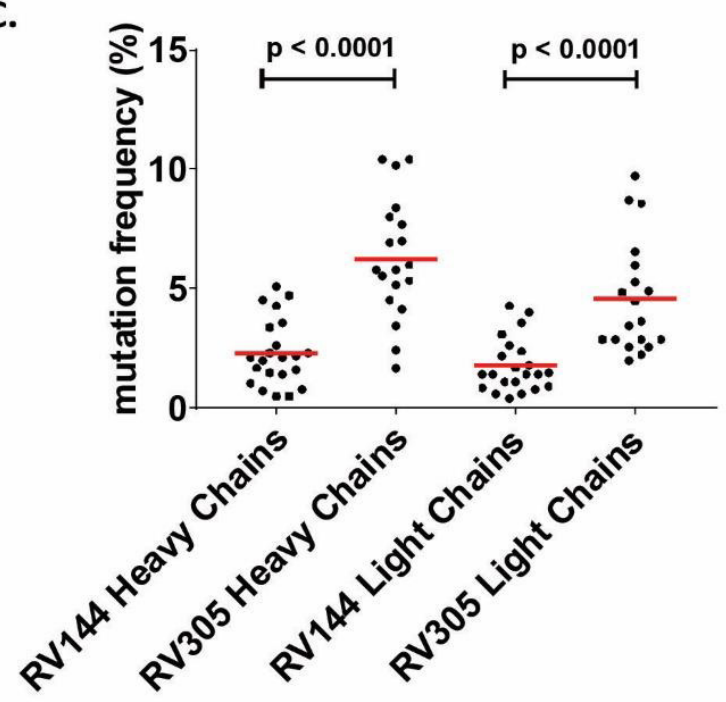

D.
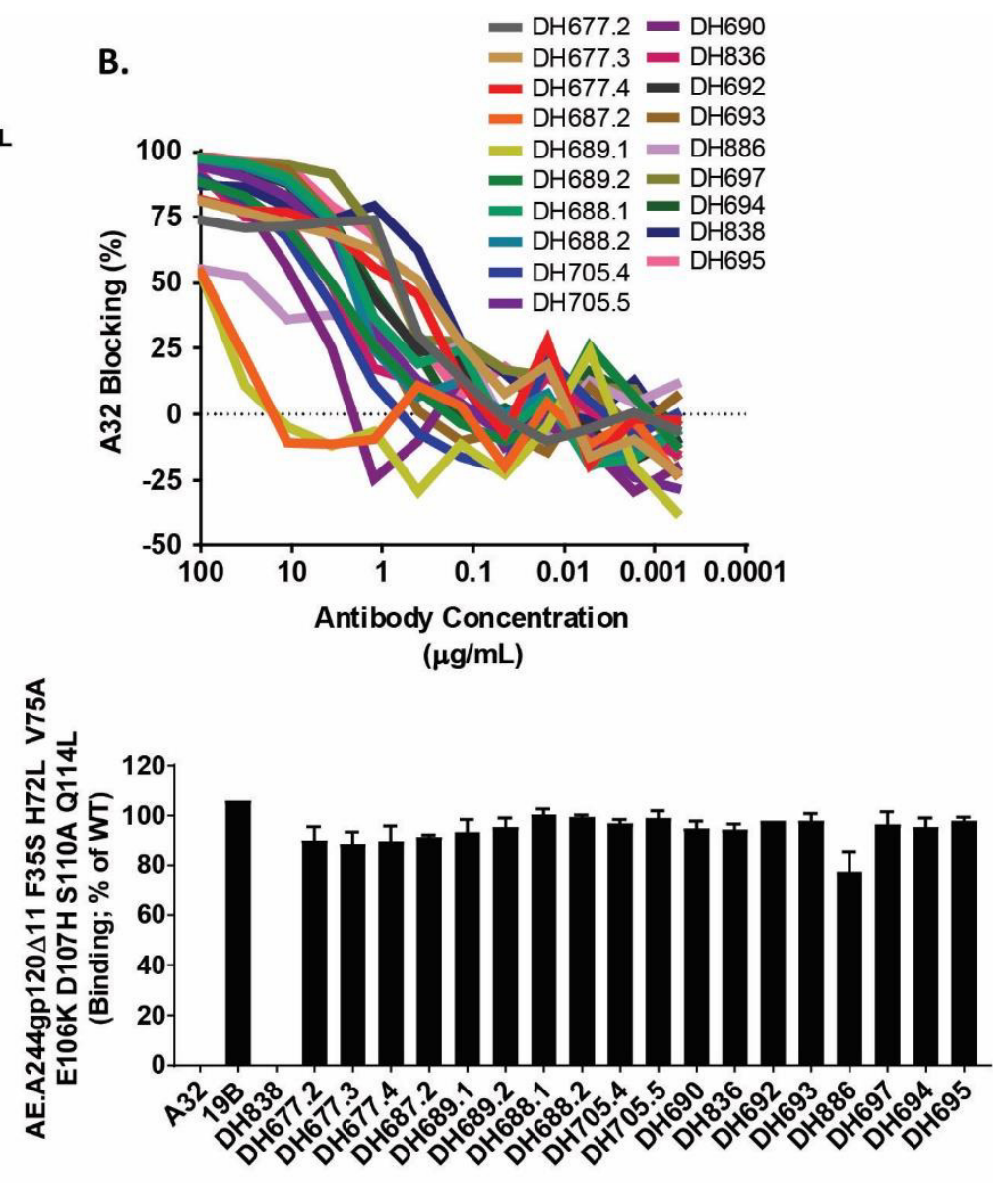

Figure 1. 
bioRxiv preprint doi: https://doi.org/10.1101/632844; this version posted May 9, 2019. The copyright holder for this preprint (which was not certified by peer review) is the author/funder, who has granted bioRxiv a license to display the preprint in perpetuity. It is made available under aCC-BY-ND 4.0 International license.

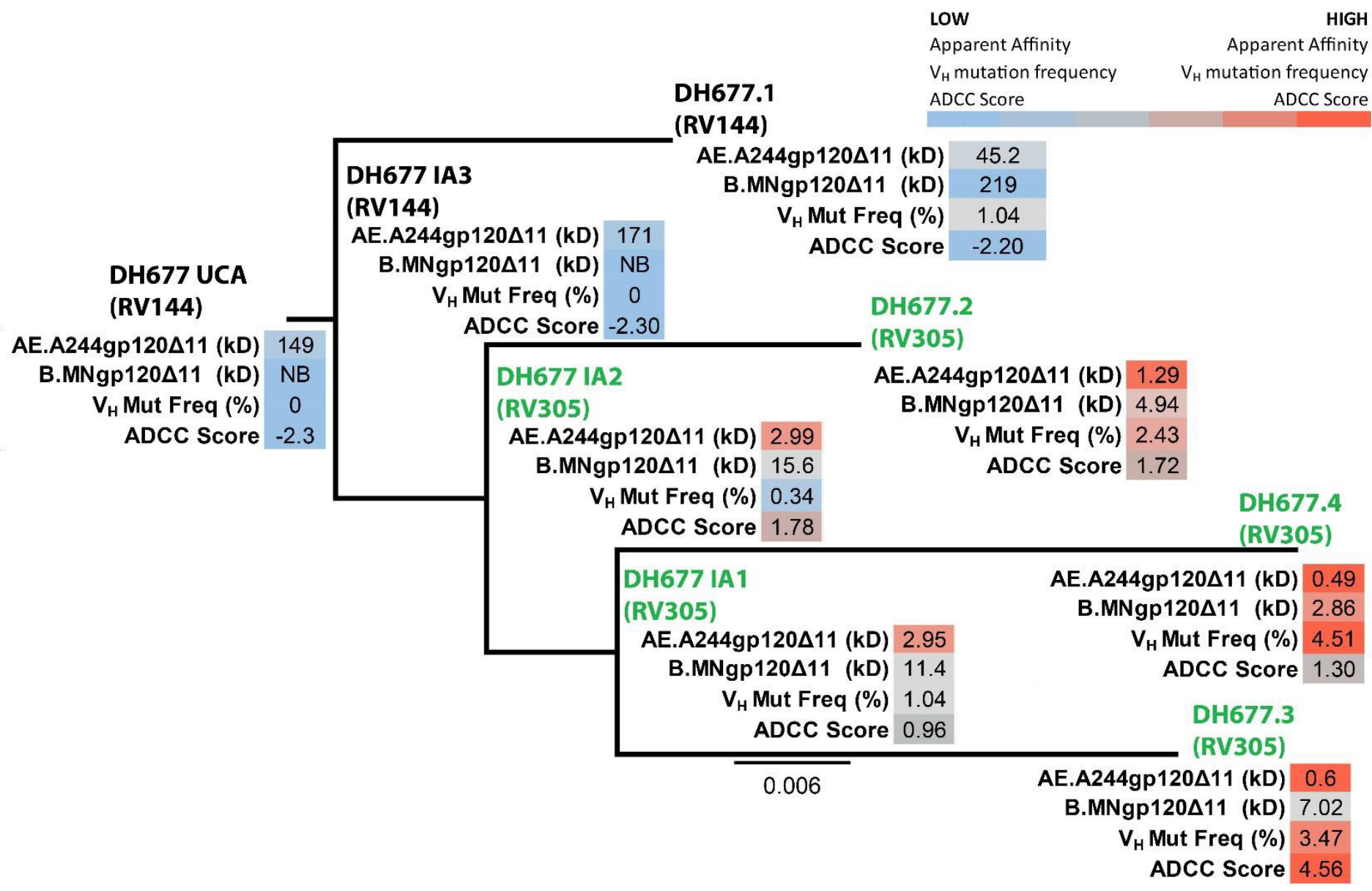

Figure 2. 
bioRxiv preprint doi: https://doi.org/10.1101/632844; this version posted May 9, 2019. The copyright holder for this preprint (which was not certified by peer review) is the author/funder, who has granted bioRxiv a license to display the preprint in perpetuity. It is made available under aCC-BY-ND 4.0 International license.

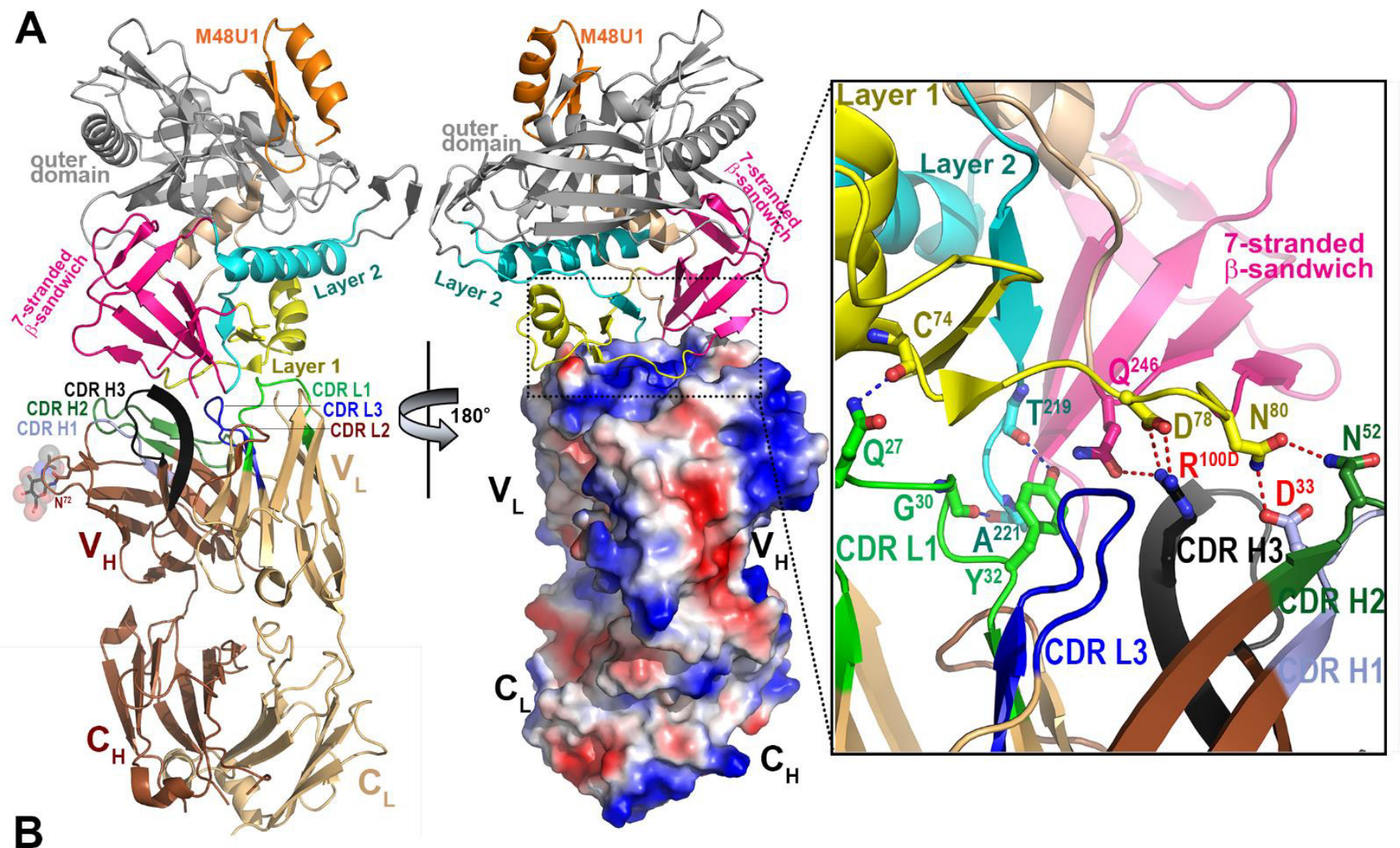

\begin{tabular}{|c|c|c|c|c|c|c|c|c|c|c|c|c|c|c|c|c|c|c|c|c|c|c|c|c|c|c|c|c|}
\hline & & & & & & & $\mathrm{H}$ & & & & $1, \mathrm{~s}$ & $\mathrm{H}, \mathrm{H}$ & & & & & & $\mathrm{H}$ & & $\mathrm{H}$ & & & & & & $\mathrm{H}$ & & \\
\hline \% conservation & 9.9 & 88.3 & 99.8 & 99.4 & 97.8 & 99.8 & 99.9 & 99.99 & $\begin{array}{ll}99.9 & 99 . \\
\end{array}$ & 9.799 & $\begin{array}{l}9.499 .9 \\
\end{array}$ & 83.4 & 95.6 & 38.2 & 93.3 & 5.5 & 99.9 & 83.4 & 99.99 & 99.89 & 99.96 & 61.19 & 99.0 & 91.0 & 99.1 & 98.4 & & 63.4 \\
\hline $\mathrm{BSA}\left(\dot{A}^{2}\right)$ & 47.2 & 6.0 & 1.2 & 26.4 & 6.2 & 6.9 & 13.8 & 68.37 & \begin{tabular}{l|l}
71.2 & 7. \\
\end{tabular} & \begin{tabular}{l|l}
.8 & 43. \\
\end{tabular} & \begin{tabular}{l|l|}
3.2 & 78.7 \\
\end{tabular} & 98.3 & 66.5 & 54.9 & 3.0 & 3.9 & 1.7 & 3.6 & 30.39 & 96.92 & 2.5 & \begin{tabular}{|l|l|}
4.1 & 4 \\
\end{tabular} & 42.0 & 11.5 & 2.4 & 72.5 & & 13.2 \\
\hline & $F^{53}$ & $A^{60}$ & $A^{70}$ & $\mathrm{~T}^{71}$ & $\mathrm{H}^{72}$ & $A^{73}$ & $\mathrm{c}^{74}$ & $\mathrm{~V}^{75}$ & $P^{76}$ & \begin{tabular}{l|l}
$\mathrm{r}^{77}$ & $\mathrm{D}^{7}$ \\
\end{tabular} & \begin{tabular}{l|l|}
$7^{78}$ & $P^{79}$ \\
\end{tabular} & $\mathrm{~N}^{80}$ & $Q^{82}$ & $1^{84}$ & $L^{86}$ & $E^{87}$ & $C^{218}$ & $\mathrm{~T}^{219}$ & $\mathrm{P}^{220} \mathrm{~F}$ & $\begin{array}{ll}A^{221} & G \\
\end{array}$ & $\mathrm{G}^{222}$ & $Y^{223} I^{\prime}$ & $\mathrm{v}^{224}$ & $\mathrm{~s}^{244}$ & $v^{245}$ & $Q^{246}$ & & $E^{492}$ \\
\hline & & & & & & & Layє & er 1 & & & 7-str & ranc & ded & $\beta-S i$ & and & Wic & & Lay & ver 2 & & & -stra & ar & led & & and & $\mathbf{V I C |}$ & \\
\hline
\end{tabular}

C

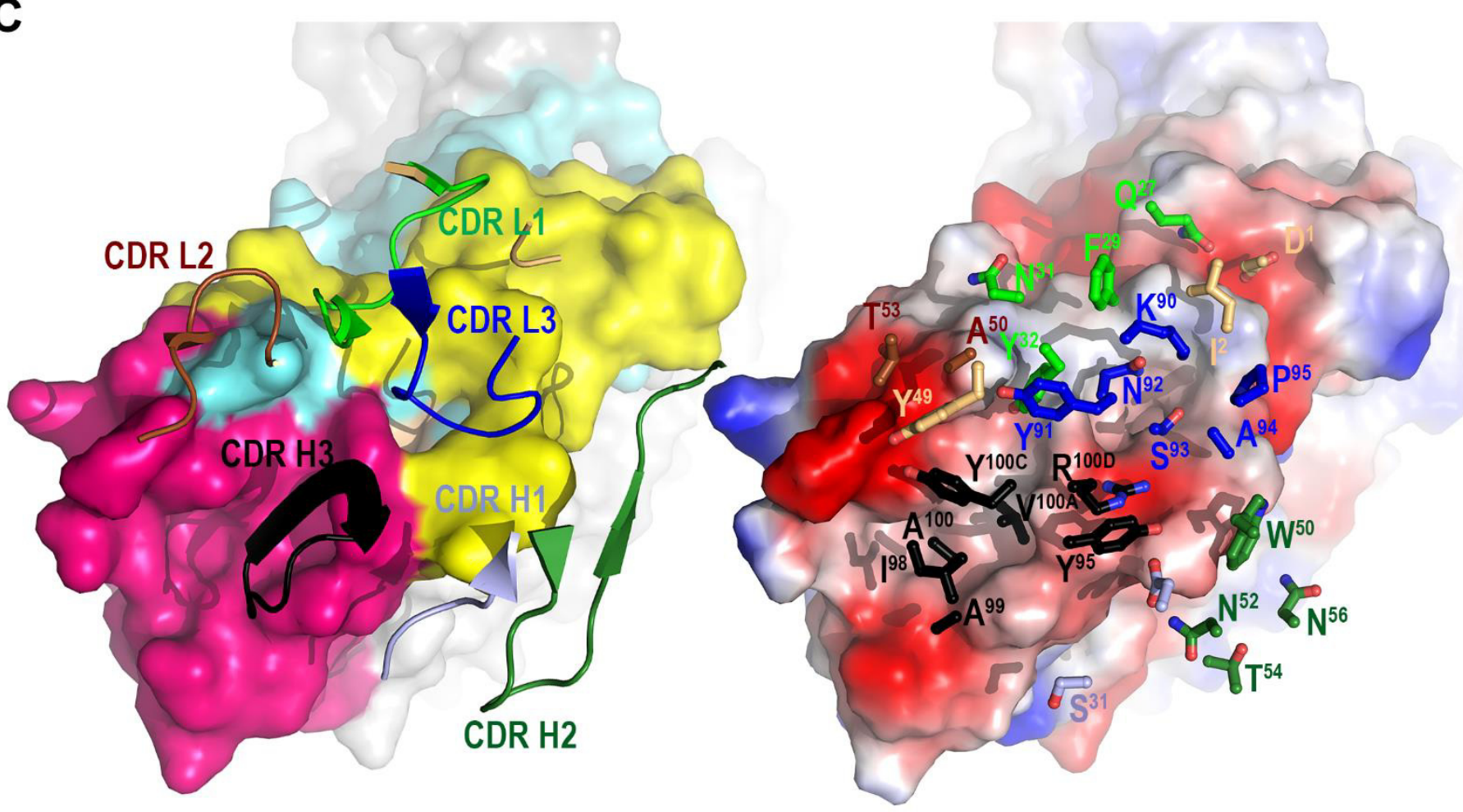

Figure 3. 
bioRxiv preprint doi: https://doi.org/10.1101/632844; this version posted May 9, 2019. The copyright holder for this preprint (which was not certified by peer review) is the author/funder, who has granted bioRxiv a license to display the preprint in perpetuity. It is made available under aCC-BY-ND 4.0 International license.
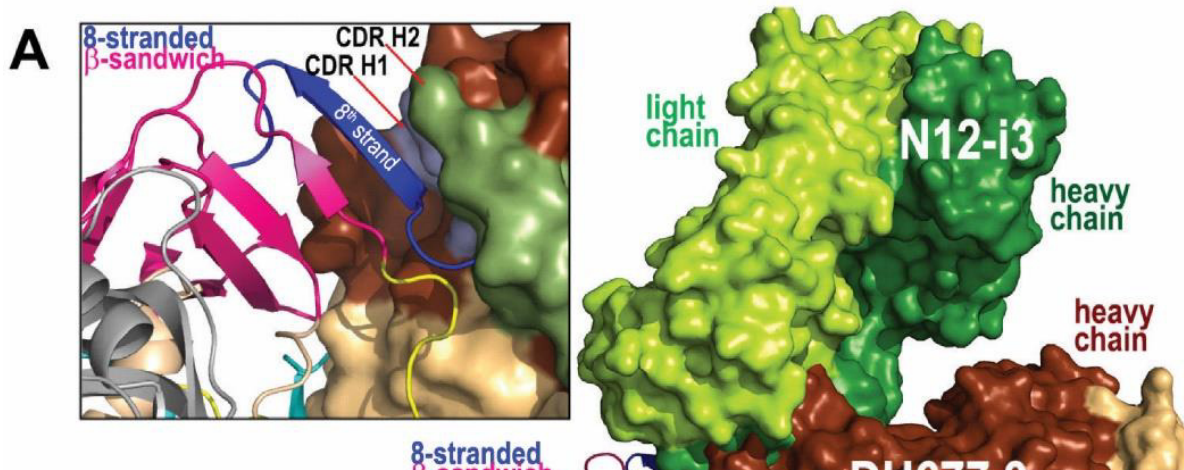

8-stranded

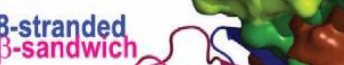

s

outer

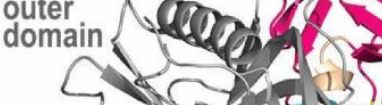

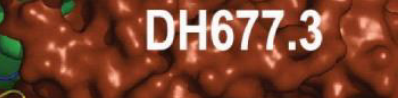
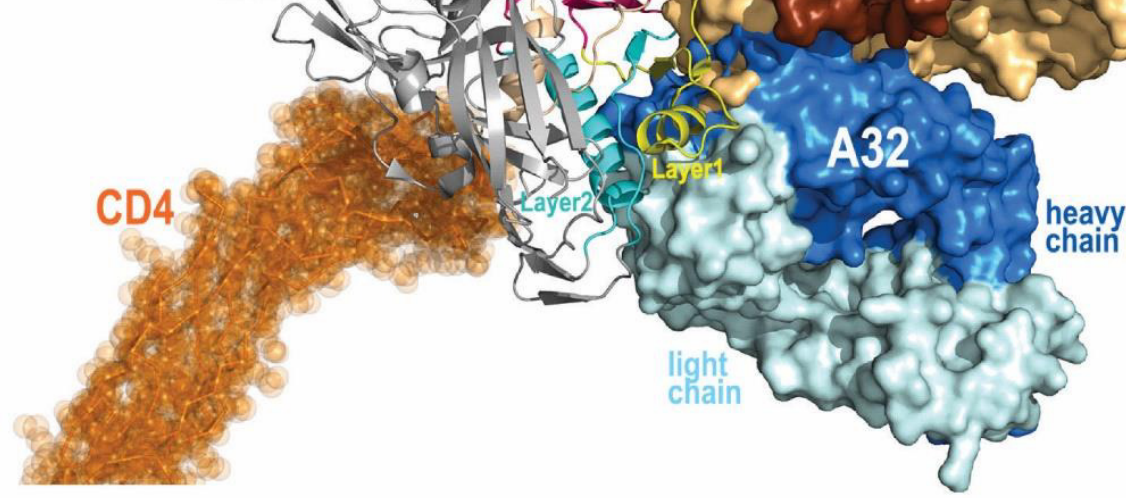

B

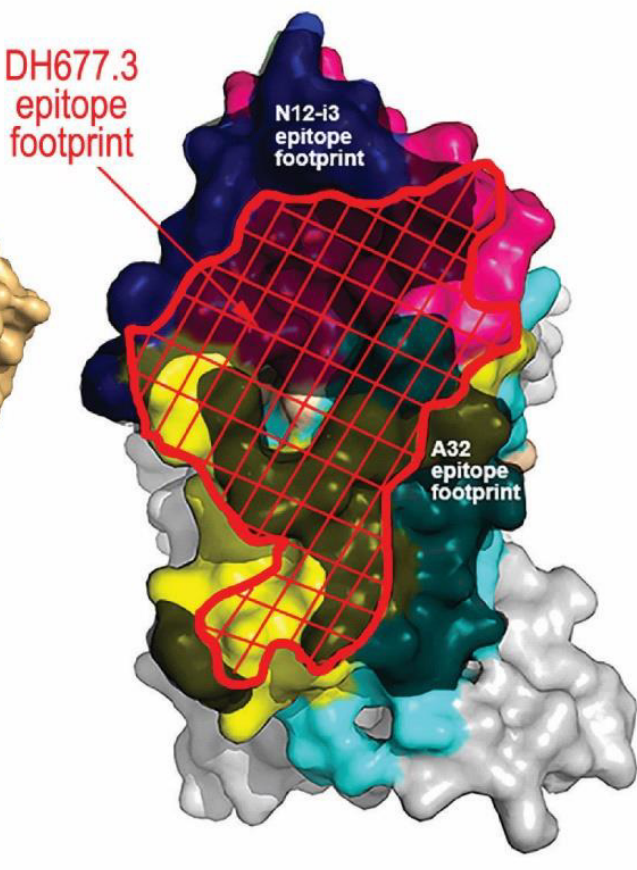

C

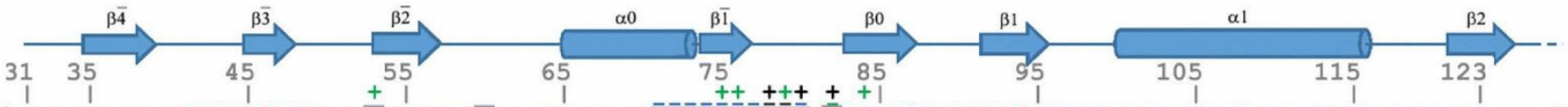

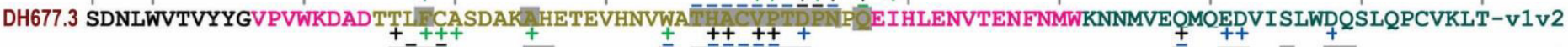

A32 SDNLWVTVYYGVPVWKDADTITFASDAKAHETEVHNV AMHACVPTPNPOEIHLENVTENFNMWKNNMVEOMOEDVISLWDOSLOPCVKLT-V1 2

N12-i3 SDNLWT'VYYGVPVWIKDADTTLFCASDAKAHETEVHNVWATHACVPTDPNPQ̈EIHLENVTENFNMWKNNMVEQMQEDVISLWDQSLQPCVKLT-v1 V2

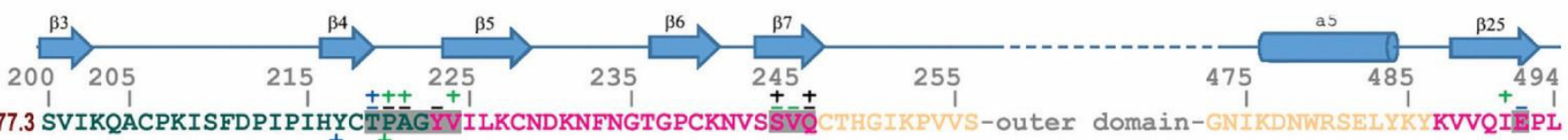
DH677.3 SVIKQACPKISFDPIPIHYCTPĀGYTILKCNDKNFNGTGPCKNVSSVQ CTHGIKPVVS-outer domain-GNIKDNWRSELYKYKVVQIĒPL A32 SVIKQACPKISFDPIPIHYCTPAGYVILKCNDKNFNGTGPCKNVSSVQCTHGIKPVVS-outer domain-GNIKDNWRSELYKYKVVQIEPL

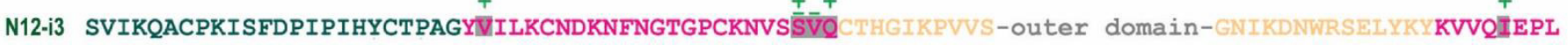

Figure 4. 
bioRxiv preprint dol: https://doi.org/10.1101/632844; this version posted May 9, 2019. The copyright holder for this preprint (which was not certified by peer review) is the author/funder, who has granted bioRxiv a license to display the preprint in perpetuity. It is made available under aCC-BY-ND 4.0 International license.

P24+

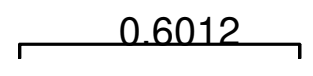

0.2481

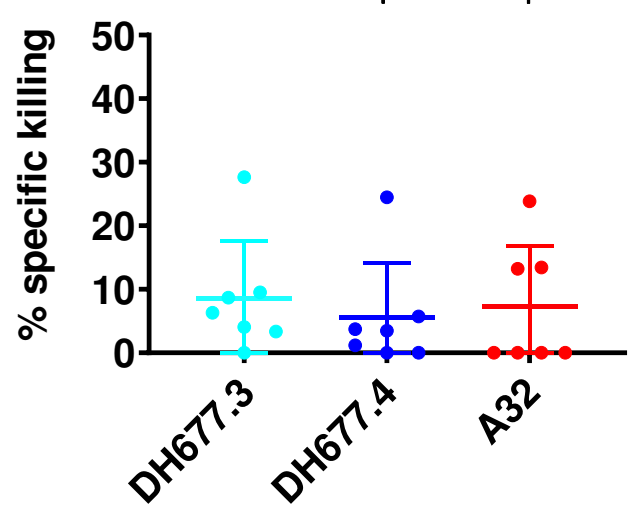

P24+CD4+
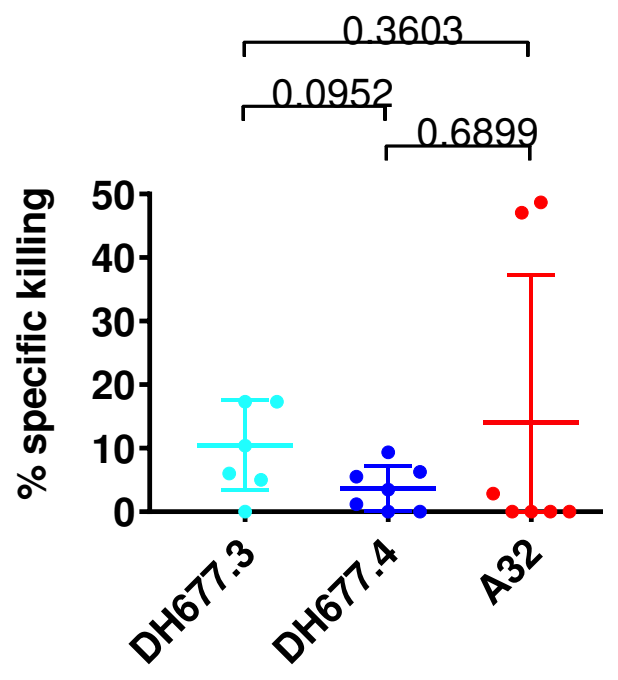

P24+CD4-
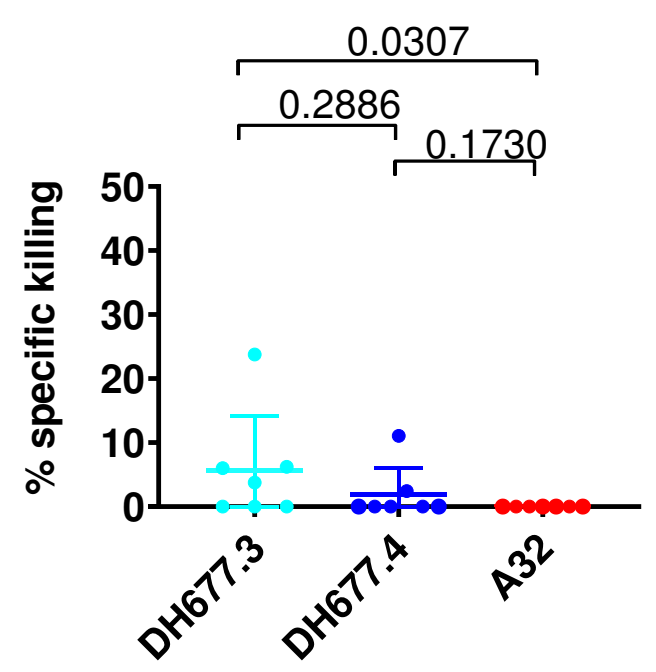

Figure 5. 
Table1: Ranking C1C2-specific antibodies by ADCC breadth and potency

\begin{tabular}{|c|c|c|c|c|c|}
\hline Rank & Antibody & Study & Score & Average AUC & $\begin{array}{l}\text { Number of } \\
\text { strains } \\
\text { recognized }\end{array}$ \\
\hline 1 & A32 & & 6.62 & 198.70 & 7 \\
\hline 2 & $\mathrm{CH} 38$ & RV144 & 6.28 & 186.56 & 6 \\
\hline 3 & DH677.3 & RV305 & 4.56 & 146.90 & 7 \\
\hline 4 & DH697 & RV305 & 2.70 & 111.98 & 7 \\
\hline 5 & DH677.2 & RV305 & 1.72 & 111.76 & 5 \\
\hline 6 & DH838 & RV305 & 1.62 & 107.24 & 4 \\
\hline 7 & DH677.4 & RV305 & 1.30 & 94.00 & 6 \\
\hline 8 & DH695 & RV305 & 0.86 & 82.94 & 7 \\
\hline 9 & DH688.1 & RV305 & 0.66 & 77.94 & 6 \\
\hline 10 & DH694 & RV305 & 0.58 & 80.18 & 5 \\
\hline 11 & DH705.5 & RV305 & 0.52 & 75.84 & 5 \\
\hline 12 & DH705.4 & RV305 & 0.46 & 75.46 & 6 \\
\hline 13 & DH690 & RV305 & 0.36 & 67.44 & 7 \\
\hline 14 & DH692 & RV305 & 0.08 & 65.14 & 6 \\
\hline 15 & $\mathrm{DH} 693$ & RV305 & 0.06 & 64.54 & 7 \\
\hline 16 & DH886 & RV305 & -0.08 & 67.96 & 5 \\
\hline 17 & DH688.2 & RV305 & -0.30 & 60.42 & 5 \\
\hline 18 & DH836 & RV305 & -0.32 & 62.52 & 5 \\
\hline 19 & $\mathrm{CH} 57$ & RV144 & -0.48 & 53.22 & 5 \\
\hline 20 & $\mathrm{CH} 90$ & RV144 & -1.06 & 38.98 & 5 \\
\hline 21 & $\mathrm{CH} 54$ & RV144 & -1.20 & 34.58 & 5 \\
\hline 22 & DH689.2 & RV305 & -1.42 & 24.54 & 6 \\
\hline 23 & DH689.1 & RV305 & -1.68 & 26.48 & 6 \\
\hline 24 & DH677.1 & RV144 & -2.20 & 16.38 & 2 \\
\hline 25 & DH687.2 & RV305 & -2.70 & 0.16 & 2 \\
\hline
\end{tabular}

